\title{
Prosodic structure between the prosodic word and the phonological phrase: Recursive nodes or an independent domain? ${ }^{1}$
}

MARINA VIGÁRIO

\begin{abstract}
In this article, a prosodic domain located between the prosodic word and the phonological phrase is argued for (the prosodic word group - PWG). This constituent groups the members of several types of compound-like expressions, but does not play a special part in the prosodic organization of clitics, and thus is argued to be (partially) distinct from the old clitic group (Hayes 1989; Nespor and Vogel 1986). The PWG is shown to play a role in the phonology of compound-like expressions in a great number of languages, belonging to different linguistic families. Evidence is multifarious, coming from segmental, tonal, duration and prominence related phenomena. Crucially, evidence is also offered against an analysis resorting to recursive prosodic words - e.g., prominence patterns at the levels of the Prosodic Word $(P W)$ and PWG may be reversed; phonological phenomena distinguishing the two domains show a difference in kind and not just in strength (Ladd 1996/2008; Frota 2000).
\end{abstract}

1. Previous presentations of this article were made at the XXII National Meeting of the Portuguese Association of Linguistics, held at Coimbra (Portugal), in October 2006, at the workshop Domínios: Prosódia e Sintaxe, held at the Universidade Estadual de Campinas (Brazil), in April 2007, at the conference Theoretical and Experimental Advances in Prosody, held at the University of Cornell, in April 2008, and OCP6, held at the University of Edinburgh, in January 2009. We are very grateful to the audiences of these meetings, as well as to Edward Flemming, Junko Ito, Aditi Lahiri, Sun-Ah Jun, Marina Nespor, Lisa Selkirk, and Stefanie Shattuck-Hufnagel for comments and reactions. Special thanks are also due to an anonymous reviewer and to Harry van der Hulst for very accurate and helpful comments on a previous version of this article. This research has been partially funded by the project SilC PTDC/LIN/66202/2006. 


\section{Introduction}

The theory of prosodic phonology (Selkirk 1984, 1986; Nespor and Vogel 1986) has proved very successful in accounting for a large body of phonological (and other grammatical) facts in the languages of the world, not only spoken but also sign languages (e.g., Nespor and Sandler 1999; Sandler 2006). Besides the function it is known to have in the linguistic systems, more recent investigation has highlighted the role played by prosodic structure in areas such as language perception and comprehension, speech production, and language acquisition (see, among many others, Morgan and Demuth 1996; Keating and Shattuck-Hufnagel 2002; Nespor and Vogel 2007; Christophe et al. 2008; Jun 2007; Wheeldon and Lahiri 2002; and references therein). Two decades after the initial proposals, many of the basic principles of prosodic phonology seem to remain largely uncontroversial. Despite the fact that the general ideas still hold, the impressive amount of work done in this area has also shown the need to introduce some modifications to the original proposals.

In this article we shall address an aspect of prosodic phonological theory that has been the focus of some discussion in the past, namely, the specific prosodic organization of the phonological material above the prosodic word $(\mathrm{PW} / \omega)$ and below the phonological phrase $(\phi)$.

In contrast with those who have defended the existence of a proper domain at this level (the clitic group or the composite group - e.g., Nespor and Vogel 1986; Vogel 2009; and others), many have argued against it and proposed to account for the relevant phonological facts via an organization of phonological material that admits recursive structures (see Section 4 for a review of the arguments in favor of this position).

Several recent studies have revisited the issue and new proposals have been made (e.g., Ito and Mester 2006, 2007; Kabak and Revithiadou 2006; Vigário 2006, 2007; Kabak and Revithiadou 2009; Vogel 2009; van der Hulst 2010). Ito and Mester propose that adjunction structures should be systematically introduced at the prosodic levels corresponding to PW and $\phi$, thus establishing a distinction between maximal and minimal projections. By contrast, Kabak and Revithiadou (2006), Vigário (2006, 2007), and Vogel (2009) argue that a proper prosodic constituent should exist distinct from the original clitic group (CG), between the PW and $\phi$. What these works have in common is the perception that, in order to account for a number of phonological facts, more prosodic structure is needed between the PW and $\phi$. These studies also defend that some limitation should be imposed on recursive structures, contrary to Kabak and Revithiadou (2009) and van der Hulst (2010), who admit recursivity in phonology. In this article we expand the analysis proposed in Vigário $(2006,2007)$. Unlike Ito and Mester (2006, 2007), Kabak and Revithiadou (2006), and van der Hulst (2010), besides defending a specific domain between the PW and 
$\phi$ on the basis of data from a significant number of languages, we also hope to demonstrate that recursive structures are empirically inadequate. Differently from Kabak and Revithiadou (2006) and Vogel (2009), we claim that this constituent crucially accounts for the prosodization of morphosyntactic words that are composed of more than one prosodic word, but not (necessarily) for the prosodization of clitics. Also unlike Ito and Mester, we account for a great variety of facts in many languages preserving the essential geometry and machinery of classical prosodic hierarchy.

This article is structured as follows. After making a brief presentation of the main aspects of prosodic phonology that are relevant for our purposes and that still hold currently (Section 3), we review what we take to be the most important problems that prosodic phonology faces today (Section 4). Some of the problems noticed are related to the elimination of the $\mathrm{CG}$, a constituent located between the PW and $\phi$ that has been argued in the literature to play a role in the prosodization of clitic-host combinations and of compounds. In Section 5, we propose that a constituent between the PW and $\phi$ should be allowed. However, given the strong arguments against the grouping of clitic-host combinations under a specific prosodic node, which are reviewed in Section 4, we propose that the constituent we are talking about is not (specifically) involved in the prosodization of clitics (not more than the PW or $\phi$ ), and, therefore, a new name should be given to this constituent. We dub this constituent the prosodic word group (PWG). Our aim in Section 5 is two-fold: (i) to provide evidence in favor of a specific prosodic organization between the PW and $\phi$; (ii) to show that recursive Prosodic Words are problematic both on empirical and on theoretical grounds, and thus do not constitute a viable alternative to the PWG. Section 6 presents a summary of our proposal and some concluding remarks.

\section{Some basic assumptions in prosodic phonology}

Most of the fundamental aspects of the early proposals on prosodic phonology (see, in particular, Selkirk 1984; and Nespor and Vogel 1986) still hold currently. First of all, it is by now currently acknowledged that many phonological phenomena in the languages of the world depend on a certain organization of phonological units. Additionally, the relevant structure is phonological rather than morphological or syntactic, even though morphological and syntactic information play a crucial role in the construction of prosodic domains (see, Truckenbrodt 2007 for a recent overview of the syntax-phonology interface; and Nespor and Vogel 1986; Peperkamp 1997; and Vigário 2003a; among others, for the role played by morphological information in the construction of the $\mathrm{PW}$ ). Another idea that we believe is still widely accepted is that prosodic hierarchy is universal, even if there is some room for language particular variation 
in what concerns the construction of phonological domains. We may note, nevertheless, that some languages have been reported to pose apparent problems to this conception, as we will see in the following section.

We will also see in the next section that there is still quite some controversy as to the exact constituents that compose prosodic hierarchy, which, according to Nespor and Vogel (1986) includes the utterance (U), the intonational phrase (I), the phonological phrase $(\phi)$, the clitic group (CG), the prosodic word $(\omega / \mathrm{PW})$, the foot $(\Sigma)$ and the syllable $(\sigma)$.

Particularly important for our purposes is the CG, a constituent located between $\phi$ and PW, which has been subject to strong criticism since closely after its first proposal (Hayes 1989).

Phonological domains are organized hierarchically, forming prosodic trees that conform to a set of well-formedness conditions, embodied in the Strict Layer Hypothesis - SLH (cf. Selkirk 1984; Nespor and Vogel 1986). The structures in (1), taken from Ladd (1996: 239), exemplify some of the configurations that are ruled out by the SLH.

(1)

a. Multiple domination

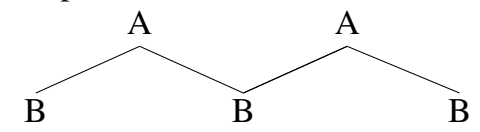

b. Heterogeneous sisters<smiles>CC=CC</smiles>

c. Skipping of levels<smiles>CC=CC</smiles>

d. Recursion<smiles>CC=CC</smiles>

Such a well-defined set of conditions on the architecture of prosodic trees means that there is a fixed and regulated organization of prosodic constituents: not only is there a limited and fixed set of prosodic constituents per tree, but their organization is such that, for instance, (i) a constituent of a given level may not dominate a constituent of a higher level, and (ii) a constituent of a given level may not dominate a constituent of the same level. It should be stressed that these two conditions are crucial for deriving some of the fundamental differences between syntactic and prosodic structures, the former having (poten- 
tially) unlimited depth and the later being flatter, since in the latter, but not in the former, the number of levels is determined by the number of existing prosodic constituents.

Another important consequence of the existence of such conditions on the formation of prosodic trees is that the same general structure is expected to obtain in every language.

The conditions stated in the SLH are currently understood as a set of ordered constraints, some of which being violable (e.g., McCarthy and Prince 1994; Truckenbrodt 1995, 1999; Selkirk 1996, 2000). As we will see in Section 3, *RECURSION is one of the constraints that is now often assumed to be violable, in contradiction with the early spirit of the SLH, and this has important consequences for the shape of prosodic trees that are presently admitted by the theory.

\section{Problems that prosodic phonology faces nowadays}

Despite the great success of the theory of prosodic phonology, a number of problems persist. In this section we review some of the most important ones.

As said above, prosodic phonology aimed at providing a general theory for accounting for the domain of (pure) phonological phenomena and of relevant phonological generalizations. Thus, the identification of phenomena that appeared to refer to domains not coinciding with any of the existing prosodic domains has led to claims in favor of new domains (see, for example, Condoravdi 1990 who proposes the domain $Z$ on the basis of Greek data; Downing 1999 who proposes a separation between the prosodic stem and the prosodic word; Pentland and Laughren 2004 who also suggest a split at the prosodic word level in Warlpiri, where the prosodic word and the phonological word are proposed to be two distinct prosodic domains - see also Section 5.2.6 below). The proliferation of constituents based on data from a single language results in an obvious weakening of the theory.

Some specific prosodic constituents were also found to apparently not play a role in the phonology of some languages, which has contributed to casting some doubts on the universal status of the prosodic tree. However, at least in some cases, a deeper look at the phonological facts of the languages at stake allows us to see that this observation is in fact incorrect. A common example of this apparent lack of evidence for a particular prosodic domain comes from French. Here the fact that word-level stress is not perceived, except in phrasefinal position, is often regarded as an indication that the language lacks the PW level. There are, nevertheless, several facts of French phonology showing the need for this prosodic level, such as tonal distribution (cf. Ladd 1996: 56; Gussenhoven 2004: chap. 13) and segmental rules, like glide formation and 
closed syllable adjustment (cf. Hannahs 1995a). A similar situation obtains in European Portuguese, where there is an apparent lack of segmental phenomena cuing $\phi$. Despite this, $\phi$ is relevant for accounting for prominence-related segmental phenomena and for pitch accent distribution (see Frota 2000); and it also plays a role in ambiguity resolutions (Frota, Severino and Vigário 2009). In other words, and as already stressed in Nespor and Vogel (1986: 11-12), the lack of known evidence for a given domain in a particular language does not necessarily mean that that domain does not play a role in a yet unknown area of the grammar of that language.

A more persistent problem has to do with the fact that the phonological hierarchy that is assumed in work by different scholars is not always the same. The variation is often correlated with the different areas of research within phonology. For example, above the PW level, the accentual phrase and the intermediate phrase coexist with the minor phrase and the major phrase, which coexist with the clitic group and the phonological phrase (see the terminology used, for example, in Pierrehumbert and Beckman 1988; Selkirk 2000; Nespor and Vogel 1986, respectively, and subsequent work). For different identifiable reasons, the variation found is also often correlated with the languages that are studied - for example, Asian languages such as Japanese or Korean are most often described with reference to the accentual phrase and the intermediate phrase or to the minor and major phrases, whereas Romance languages, Greek and Turkish are often described with reference to the clitic group and the phonological phrase (see, also, Truckenbrodt 1999; Selkirk 2000).

Notice that the adoption of a specific term or set of terms does not necessarily mean that the constituents under reference are meant to be distinct from the constituents of the apparently same level in another terminological tradition. The use of each of these three pairs of terms is very widely spread, with costs for cross-linguistic comparison, as well as for the comparison between analyzes of specific languages. As pointed out in Ito and Mester (2007), additionally, some terminology is motivated by language specific phenomena, as in the case of the accentual phrase, accent group or the tone group, making it difficult to extend its use to other languages lacking the kind of phenomena that suggested these labels.

Besides the problems related to cross-linguistic and cross-studies comparison, the state of affairs described above also induce doubts about the universal nature of (a single) prosodic structure.

The principles, embodied by the SLH (Strict Layer Hypothesis), governing well-formed prosodic trees have also been questioned (e.g., Inkelas 1990; Ito and Mester 1992; Selkirk 1996, among others). Arguing against the existence of the CG as a proper domain of prosodic hierarchy, a number of studies defend the idea that the integration of clitics in the prosodic tree may cause the violation of Exhaustivity (i.e., no skipping of levels), displaying configurations 
like those in (2) (see, e.g., Selkirk 1996; Kleinhenz 1996; Peperkamp 1997; Hall 1999, among many others).

(2)<smiles>O=C(O)O</smiles>

It is also admitted that Recursion may be violated. For example, recursive structures are claimed to be necessary at the level of the intonational phrase (I) (in the organization of coordinate sentences - Ladd 1992, 1996; and with certain types of parentheticals and relative clauses - Frota 2000; Vigário 2003b), and at the level of the PW (in the organization of compound-like expressions, as exemplified in (4) - e.g., McCarthy and Prince 1994; Booij 1995; Leben and Ahoua 1997; Vigário 2003a).<smiles>O=C[Co]</smiles>

A note should be made at this point on the difference between structures where the higher node dominates two (full) constituents of the same type, as in (3), and the structure in (4), where a constituent of a lower level is adjoined to a given level, as has often been proposed for clitics in several languages (e.g., Inkelas 1990; Zec and Inkelas 1991; Selkirk 1996; Booij 1996; Peperkamp 1997; Vigário 2003a).<smiles></smiles>

In our view, these are clearly two distinct prosodic configurations. Van der Hulst (2010) distinguishes these two types of structures using the terms balanced recursion and unbalanced recursion, for configurations like those in (3) and (4), respectively. In fact, the two types of configurations yield different phonological behavior: Booij (1996), Peperkamp (1997), Vigário (2003a), among others, have shown that material adjoined to a given prosodic category $\mathrm{X}$ fall outside the domain of rules that apply with reference to $\mathrm{X}-$ for example, clitics adjoined to the PW in Dutch, unlike clitics that incorporate into the host's PW, are not included in the domain of resyllabification in that language, which is the PW; however, the same is not true of configurations like (3); for example, Frota (2000) proposes that the domain of resyllabification in European Portuguese is the intonational phrase; and resyllabification still applies across intonational phrases that are grouped within a compound intonational 
phrase. As we will see, the proposal made in this article crucially impinges on balanced recursion only.

In order to account for these new types of prosodic configurations, Selkirk (1996) proposes that the conditions on the formation of prosodic trees should be treated within an optimality theoretic framework as a set of constraints, some of which are violable (see 5, taken from Selkirk 1996, where $\mathrm{C}^{\mathrm{n}}$ stands for some prosodic category). And this idea has been widely adopted.

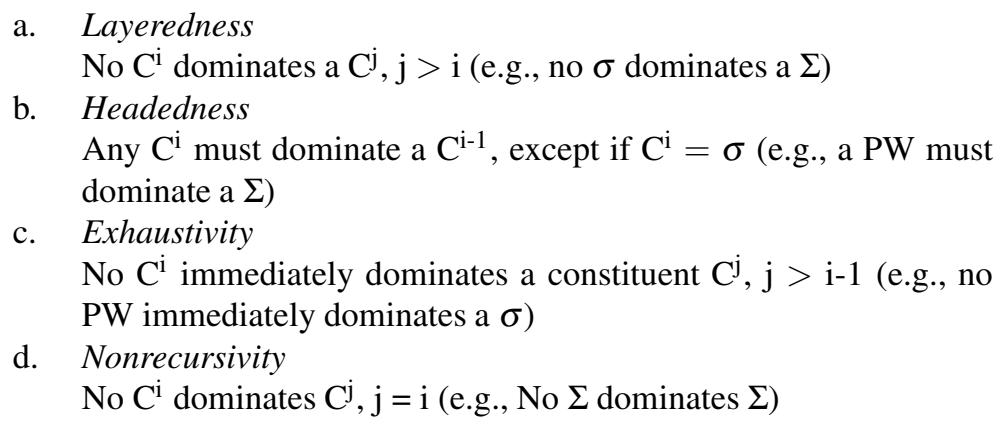

The relaxation of the SLH represents a weakening of the general theory of prosodic domains: the structure is now less fixed; the intrinsic difference between prosodic structure (which is flatter) and syntactic structure (which is deeper) becomes less apparent; recursive structures are now assumed to be rather common in the languages of the world; there seems to be no general mechanism that limits recursivity; the difference between the levels of prosodic organization is now less clear.

The present article bears on all these issues, concentrating on the level of prosodic structure between the prosodic word and the phonological phrase. We will show that in many languages there are several phonological facts that refer to a prosodic domain between the PW and $\phi$, thus pointing to the universal status of this level of prosodic hierarchy; we will also argue that this is a basic constituent of the prosodic hierarchy, instead of being obtained via recursion, and by doing so, we are eliminating an important source of violation of *RECURSION.

In the next section, we briefly review the evidence against the clitic group as proposed in the past, and show that these are all related to the prosodization of clitics, but not of compounds, which have also been proposed to be grouped inside the clitic group. 


\section{Specific problems of the clitic group}

\subsection{Early evidence for the clitic group}

The idea that there is a prosodic constituent between the PW and $\phi$ was first defended by Hayes (1989), and adopted in Nespor and Vogel (1986), and much subsequent work (e.g., Vogel 1990, 1991; Hannahs 1995a; Nespor 1999a; Schwindt 2000; Kabak and Vogel 2001; to mention but a few). This constituent, was primarily seen to include a PW plus clitics (hence the name clitic group CG).

The basic motivation for the CG is similar in nature to that supporting the other prosodic constituents, that is, the occurrence of phonological facts whose context depends on a particular phonological structure of a given level. An example of a process that has been argued to depend on the CG is stress assignment in Latin. As illustrated in (6), taken from Nespor and Vogel (1986: 146), in this language, enclitics are included in the domain that counts for the computation of stress. Within this model, this means that the domain for wordlevel stress assignment is not the PW but the domain that includes both the clitics and the PW, that is the CG.

$$
\begin{array}{llll}
\text { vírum } & \text { virúmque } & \text { vídēs vidésne } \\
\text { the man-ACC } & \text { and the man-ACC } & \text { you see } & \text { do you see? }
\end{array}
$$

Several other phenomena involving clitic-host combinations are claimed in Nespor and Vogel (1986) to have the CG as their domain, including segmental processes in Italian, Greek and Catalan, vowel harmony in Turkish, and stress readjustment in Greek.

Besides host+clitic combinations, the $\mathrm{CG}$ has also been proposed to group the internal PWs of compounds, which behave differently from non-compound word combinations (e.g., Vogel 1990 for Hungarian; Hannahs 1995b: 3.4.2 for French; and Kabak and Vogel 2001 for Turkish - see also Section 5.3 below). ${ }^{2}$

\subsection{Arguments against the clitic group}

Since closely after its first integration within the prosodic tree, the CG has been subject to a series of criticisms. Reviews of most of these criticisms can be found in Booij (1996), Peperkamp (1997), and Vigário (1999, 2003a: 1.3). In this subsection we summarize the major problems noticed in the literature.

2. See also Vogel (2009) for the proposal that the composite group (which essentially corresponds to the old clitic group) is also relevant for the organization of compounds in English and other languages. 
Inkelas (1990) suggests that the evidence for the CG as a domain distinct from PW can be reinterpreted in the light of the distinction between PWs (which do not include clitics) and post-lexical PWs (which may include clitics), and between lexical phonological rules and post-lexical phonological rules. In her view, the CG should be eliminated on the basis of economy (see also Booij 1988, and Selkirk 1996: note 3). Vigário (2003a), for instance, shows that this reinterpretation allows a straightforward explanation for the main facts of the phonology of clitic+host combinations in European Portuguese, and provides systematic evidence for the independent need of the separation between lexical and post-lexical phonological components.

A number of facts from several languages have also been argued to show that clitics may attach to prosodic levels higher than the CG, namely I and $\phi$ (e.g., Inkelas, 1990; Selkirk, 1996; Kleinhenz, 1996; Peperkamp, 1997; Hall, 1999). Since the position of constituents within prosodic trees is assumed to be fixed and universal, such facts are seen to indicate that there is no specific prosodic domain responsible for the organization of clitic-host combinations.

Another serious problem for the CG approach follows from the observation that there are asymmetries in the relation that enclitics and proclitics establish with their hosts in many languages (e.g., Booij 1996, for Dutch; Peperkamp 1997, for Italian; Kleinhenz 1996 and Hall 1999, for German; Vigário 1999, 2003a, for European Portuguese). For example, in European Portuguese there is strong evidence that enclitics incorporate into the host PW, since enclitics behave like stressless syllables at the right edge of the PW, while the syllables at the right edge of the host do not behave like PW-final; whereas proclitics adjoine to the host $\mathrm{PW}$, since not only proclitics but also the elements at the left edge of the PW display the phonology of PW-initial elements (see the configuration in 7, taken from Vigário 2003a).

(7)

a.

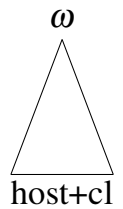

b.

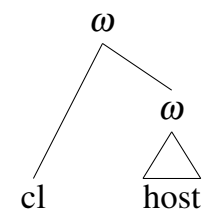

Notice that enclitics and proclitics have also been claimed to attach to distinct prosodic constituents in the same language (see Kleinhenz 1996, and Hall 1999, for German). As pointed out by Kleinhenz, this type of asymmetries cannot be accounted for under the CG hypothesis. ${ }^{3}$

3. Another problem found in the early proposals (e.g., Nespor and Vogel 1986) is that clitics are integrated within the CG with the status of PWs. This is problematic because clitics are phonologically deficient and do not show many of the properties of PWs. It must be noticed, 
Acknowledging all these arguments, we believe that there is no unique prosodic domain or prosodic configuration for clitic-host combinations (for instance, contra Vogel 2009). In other words, in our view clitics do not provide a basis for positing a prosodic constituent between the prosodic word and the phonological phrase.

We should notice, nevertheless, that all the problems pointed out against the CG have to do with the prosodization of clitics. However, as said above, this prosodic domain has also been claimed to be relevant for the prosodization of compounds (e.g., Vogel 1990; Hannahs 1995b; Kabak and Vogel 2001), a fact that will be explored in this article.

\subsection{New problems created with the elimination of the $C G$}

The ban of the CG from the set of prosodic constituents has brought new problems.

First of all, the elimination of the CG is done at the expense of allowing prosodic configurations that were previously impossible. The prosodization of clitics often involves the emergence of adjunction structures, with the skipping of prosodic levels (see $7 \mathrm{~b}$ above); and the prosodization of compounds often involves the creation of recursive structures, as in $\left.\left((\text { light })_{\omega} \text { (house }\right)_{\omega}\right)_{\omega}$ (taken from McCarthy and Prince 1994: 85). Thus, not only more structural configurations are allowed, but also the prosodic structure is less fixed, and consequently the theory is less constrained.

In addition to this, the two supplementary prosodic configurations that are allowed contribute to blur a noticeable distinction between the prosodic structure, which is flatter and limited, and the syntactic structure, which is deeper and potentially unlimited.

In the case of clitic-host combinations, we do not see a way of accounting for the phonological facts without admitting adjunction structures, at least at the level of the PW. In fact, the phonology of clitic-hosts combinations suggests that it is not possible to do without adjunction structures, since simply saying that clitics directly attach to the clitic or composite group, as in Vogel (2009), does not seem to account for the fact, observed in many languages, that for instance proclitics may show the phonology found in PW initial positions, while the initial positions of the PWs to which they attach still behave like PW initial (see Selkirk 1996 for the Serbo-Croatian dialect of Šrem, Mačva; Booij 1996

however, that the assumption that clitics are dominated by the PW node follows from the Strict Layer Hypothesis requirement disallowing the skipping of levels. Once the SLH is relaxed, and the Exhaustivity is taken to be a violable constraint, there is no reason to assume that clitics are PWs. In other words, this problem could be solved without eliminating the CG from the prosodic hierarchy (see also Vogel 2009). 
for Dutch; and Vigário 2003a: Chap. 5 for European Portuguese). This state of affairs results from the fact that (lexical) clitics are defective objects, lacking PW status, but need, nevertheless, to be integrated in the prosodic structure in some way. According to the phonological evidence, the system seems to admit two possible ways of accomplishing this: one is via the incorporation into the prosodic host, the other one is via adjunction to the prosodic host.

The same is not true of compound-like structures. First of all, there is a straightforward alternative to recursive structures, which is to allow (some) compound-like expressions to be grouped within a specific phonological domain, a constituent properly included in the set of constituents that form the prosodic hierarchy. ${ }^{4}$

Besides the fact that there is a good alternative to the analysis resorting to recursive structures, we hope to show below that in fact this is the only one that is empirically adequate. For instance, in Section 5 we will show that the rule that assigns prominence at the level of PW may differ from that assigning prominence at the level that groups compound-like structures. This behavior is predicted under a theory whereby compound-like expressions form a domain distinct from PW. By contrast, as far as we can see, this cannot be accounted for under an analysis involving recursive nodes, where it is expected that the higher recursive node displays the same properties as its daughters, and only a difference in the strength of these properties is found (e.g., Ladd 1996: 246). In the next section we develop this idea: we provide empirical evidence showing the need of a constituent distinct both from PW and from $\phi$; crucially, evidence is also offered against the view that recursive structures are capable of accounting for the data found cross-linguistically.

\section{Towards a revision of the set of prosodic constituents}

\subsection{A specific domain between the prosodic word and the phonological phrase}

The general idea that we will defend in this section is that a proper constituent of the level of the clitic group (between PW and $\phi$ ) is needed. As far as we

4. Notice that the fact that compounds may display distinct prosodic configurations is not problematic for this view. Indeed, what is relevant in this respect is to understand the conditions under which compound-like expressions are differently organized. We should point out, further, that the units at stake are not necessarily (morphologic or syntactic) compounds. As we will see throughout Section 4, the class of expressions that involve PW combinations that form a phonological domain distinct from $\phi$ may be much larger than that of compounds, including for instance derived words. In order to understand what kinds of combinations of PWs may form a domain lower than $\phi$, aspects related to the syntactic configuration under which these expressions appear, their distinct degrees of lexicalization, as well as their frequency, must be taken into account (see Section 4.4 further below). 
know, this idea was first presented in two different places simultaneously by Kabak and Revithiadou (2006) and Vigário (2006). Although part of the general idea is identical, the empirical basis, and some important details in the argumentation and proposal are not. Here, we develop the work started in Vigário (2006, 2007), based on a large number of languages, which already integrates some of the Turkish facts also referred to in Kabak and Revithiadou's work. Importantly, to the best of our knowledge, this is the first time that clear-cut evidence against recursive Prosodic Words is offered.

As said above, we claim that a constituent is needed between the PW and $\phi$. However, what this constituent groups are PWs, and not necessarily clitic-host combinations. Therefore, we believe that calling it clitic group is inappropriate.

Given its nature, we will call this domain prosodic word group (PWG). In fact, as we will show below, this constituent groups PWs that display some properties distinct from the $\mathrm{PW}(\mathrm{G}) \mathrm{s}$ that are directly dominated by $\phi$. The name proposed is therefore intuitive, because it reflects the type of constituents included inside this domain. In addition, such a name preserves the terminological coherence of the prosodic hierarchy assumed in Nespor and Vogel (1986) and much of the work that followed within prosodic phonology. It is also intended to be somewhat conservative, since part of the name of the old constituent placed at the same level is preserved. Finally, it reflects in a better way the distinction between this constituent and the one immediately below (PW), when compared to alternatives such as maximal/minimal $P W$ and major/minor $P W$. For all these reasons, we also think that prosodic word group is a better term than phonological cluster or the composite group (Kabak and Revithiadou 2006, and Vogel 2009, respectively).

In the following subsections, we provide evidence for this level of prosodic constituency. Our contention is that, regardless of the particular name that such a constituent is given, there must be a prosodic domain between the PW and $\phi$. Furthermore, we argue that recursion is not the adequate way to derive it.

\subsection{Cross-linguistic evidence for the prosodic word group}

In this subsection, we collect empirical evidence for the existence of a prosodic constituent that may include more than one PW, but that behaves differently from $\phi$ s and from what would be expected of a recursive PW. The data come from several typologically distinct languages, thus strengthening the hypothesis that this is a proper domain of prosodic hierarchy.

5.2.1. European Portuguese. Vigário (2003a: Chap.6) systematically describes a wide number of constructions involving PW combinations with a specific behavior in European Portuguese, that is the elements that form these 
constructions show a phonological behavior that is distinct from that found in other PWs that are grouped under $\phi$. In that work, the account for the specific behavior of these PW combinations resorts to recursive structures at the level of the PW, like those in (3) above. Mostly based on data presented there, we will try to show that the constituent under analysis has all the properties of a proper phonological domain, which, however, does not coincide with the PW or $\phi$. Therefore, given the problems noticed above that arise with recursive structures, we propose that the relevant data are better analyzed with reference to the prosodic word group.

For space limitations, we will not demonstrate the PW status of the internal members of what we consider here to be the PWG. We refer to Vigário (2003a: chaps. 5 and 6) for a systematic discussion of these matters. We should note, nevertheless, that the evidence for the prosodic status of these elements is extremely rich, coming from (i) the perception/intuition of word-level stress; (ii) segmental phenomena cueing stressed and stressless vowels, such as the absence or presence of vowel reduction and semivocalization; (iii) segmental and suprasegmental phenomena cuing both the right edge and the left edge of the PW; (iv) pitch accent distribution; and (v) deletion processes referring to the PW, namely clipping and deletion under identity, among others.

The constructions at stake are illustrated in (8): in (8a) we have a complex verbal expression with an internal pronominal clitic, forming a mesoclitic construction; and in (8b) we have a derived word with a stressed prefix..$^{5}$ (Here and in what follows, the stressed vowel is signaled in caps where relevant; notice that acute stress on the vowel does not signal every stressed syllable)

$$
\begin{aligned}
& \text { a. dIr-se-Ia 'we would say' } \\
& \text { b. prÉ-acentuAl 'pre-stressed' }
\end{aligned}
$$

The first type of evidence showing that the constituent that dominates the whole structure differs from $\phi$ comes from the perception/intuition of stress relations. The example in (9) illustrates this: in (9a), hiper is a root in a root compound (or a stressed prefix within a derived word) ${ }^{6}$; in (9b), hiper is the clipped form of hipermercado ('hypermarket').

(9) a. (context: A person talking about molding objects of different sizes)

$$
\begin{aligned}
& O \text { híper-monstruoso está lindo! } \\
& \text { the extra-big is beautiful } \\
& \text { 'The extra-big one is beautiful!' }
\end{aligned}
$$

\footnotetext{
5. See Vigário (2003a: 3.6 and 3.2) for the phonological behavior of mesoclitic structures and derived words with stressed prefixes, and Chap. 4 of that work, for an analysis of mesoclisis.

6. See Vigário (2003a: Chap. 6) and references therein for a discussion on the morphological separation of prefixes and roots.
} 
b. (context: A person talking about a new hypermarket)

$O$ híper monstruoso está lindo!

the hyper(market) enormous is beautiful

'The enormous hypermarket is beautiful'

These two examples contrast as to the perceived level of prominence in hiper: in (9a) it has a lower degree of perceived prominence than that in (9b).

Such a difference in prominence can be captured under an analysis whereby the two structures are differently prosodized. In the present account, this is obtained via the prosodic grouping of the first type of word sequences under a single PWG, unlike the second one (see 10). ${ }^{7}$

$$
\begin{array}{ll}
\text { a. } & ((\text { o hiper }- \text { monstruoso }) \mathrm{PWG}) \phi \\
\text { b. } & ((\text { o híper }) \mathrm{PWG}(\text { monstruoso }) \mathrm{PWG}) \phi
\end{array}
$$

Perception/intuition also allows us to conclude that the prominent element within the PWG corresponds to its rightmost PW. This can in fact already be inferred from the descriptions found in the literature on European Portuguese compound stress, where both the weaker stresses of non-final words and the main stress on the final word of the compound are reported (e.g., Gonçalves Viana 1883; Pereira 1999; Vigário 2003a).

Another type of evidence pointing in the same direction comes from vowel deletion processes in $\mathrm{V}-\mathrm{V}$ sequences across words.

As shown in Frota (2000), V1 deletion is conditioned by V2 phrase-level prominence. The segments that may undergo deletion are word-final stressless back vowels, [u] and [e]. In Vigário (2003a) it is shown that similar sensitivity to the presence of a certain level of stress on V2 is found when V1 is an underlying non-back high vowel (corresponding to an orthographic $e$ ), and is in PW final position, within what we now interpret as a PWG (see the formalization in 11, adapted from Vigário 2003a: 226). In the following paragraphs we describe the relevant facts concerning the application/blocking conditions of this rule.

$$
\begin{aligned}
& \text { Non-back vowel deletion } \\
& {\left[\begin{array}{c}
\mathrm{V} \\
- \text { high } \\
- \text { back }
\end{array}\right] \rightarrow \varnothing /\left[\ldots[\ldots-]_{\omega} \ldots\right]_{\mathrm{PWG}}}
\end{aligned}
$$

In non-compound-like contexts, the PW final $-e$ is deleted regardless of what follows, and consequently regardless of V2 stress (see 12). ${ }^{8}$

7. Note that under this proposal a single PW that is not part of a compound-like expression must also be dominated by the PWG given the need to satisfy Exhaustivity (see Section 2 above). PWGs may therefore dominate a single PW, in the same way as $\phi$ s may dominate a single PWG, and Is may dominate a single $\phi$. 


$$
\begin{array}{llr}
\text { bEbe } & \text { '(he) drinks' } \\
\text { bebe vinho } & \text { '(he) drinks wine' } \\
\text { bEbe Água } & \text { '(he) drinks water' } & \text { ??[j]/- }
\end{array}
$$

However, there are two contexts where V1 deletion is regularly blocked, when followed by another vowel. One is when the $-e$ final word corresponds to the host of an enclitic. Here, deletion does not apply because the structural description of the rule is not met: the vowel is not in fact in PW final position, given that enclitics undergo prosodic incorporation into the previous PW (see 13). ${ }^{9}$

$$
\text { bEbe-o } \quad(b e b[j] o) \omega \quad \text { 'drink it' }
$$

The second context where deletion regularly fails to apply is when V2 bears a level of prominence that we interpret here as the PWG prominence, and both vowels are inside the same PWG. This is exemplified in (14). In (14a) grande área is a compound and V1 deletion is blocked due to the fact that V2 bears the PWG prominence; in (14b), by contrast, grande área is a regular syntactic word combination, where the adjective grande is a modifier of the noun área; in this configuration, grande and área each form their own PWG, and thus there is no context for $-e$ deletion blocking.

$$
\begin{aligned}
& \text { a. A penalidade ocorreu fora da grAnde [j]/*- } \\
& \text { the fault happened outside of-the penalty } \\
& \text { Área do adversário! } \\
& \text { area of-the adversary } \\
& \text { 'The fault happened outside the penalty area of the adversary!' } \\
& \text { b. Esse campo tem uma grAnde Área de jogo. ??[j]/- } \\
& \text { that camp has a great area of play } \\
& \text { 'That camp has a great playing area.' }
\end{aligned}
$$

In (15a) and (15b), we represent the different structural and prominence relations displayed by the constructions in (14a) and (14b), respectively.

a. ((grAnde Área) $\mathrm{PWG}) \phi$

$$
\begin{array}{lll}
w & s & \text { PWG-level prominence } \\
& s & \phi \text {-level prominence }
\end{array}
$$

b. ((grAnde) $\mathrm{PWG}($ Área $) \mathrm{PWG}) \phi$

$\begin{array}{lll}w & s & \text { PWG-level prominence } \\ & s & \phi \text {-level prominence }\end{array}$

8. Here and in the following examples '-' marks vowel deletion; notice, furthermore, that when the vowel does not delete, it typically semivocalizes, forming a rising diphthong with the vowel of the following word, a regular behavior found elsewhere in EP phonology.

9. See Vigário (2003a: Chap. 5) for other facts supporting this particular prosodization of enclitics in European Portuguese. 
Notice that the same behavior is found even if Word 2 does not bear $\phi$-level stress, as shown in (16), where onze avos is a derived word with a special kind of suffix, forming a stress domain independent from the morphological base (see Vigário 2003a: Chap. 6 for discussion), and onze ovos is a regular syntactic combination of a numeral and a noun.
Avos finAis
$[\mathrm{j}] / *_{-}$
eleventh-pl final-pl
'eleventh final part of a competition'
b. Onze Ovos estragAdos
$? ?[\mathrm{j}] /-$
eleven eggs spoiled
'eleven spoiled eggs'

The relevant prosodic structure is represented under (17), where we also indicate the prominence relations at the levels of the PWG and $\phi$.

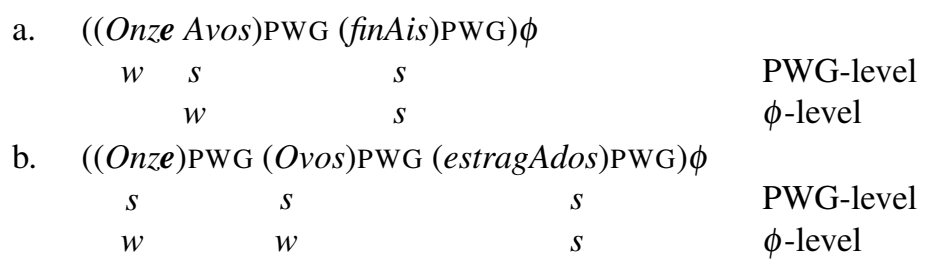

These examples show that sequences of PWs that are non-final within $\phi$ may show distinct degrees of prominence. Such a state of affairs cannot be accounted for if it is assumed that the PWs are always directly grouped under $\phi$.

The relevance of PWG-level of prominence is further supported by the fact that $-e$ deletion becomes again (nearly) obligatory when a stressed V2 is internal to the PWG, and thus does not bear the PWG prominence. This can be seen in the examples involving acronyms given in (18), where deletion is blocked when $-e$ is followed by the vowel that is assigned the compound's stress (in Eme), but applies when the stressed vowel that follows is internal within the PWG. ${ }^{10}$

$$
\begin{aligned}
& \text { RFM (Err } \underline{\boldsymbol{e}} \text { Ef } \underline{\boldsymbol{e}} \text { Eme) } \mathrm{PWG} \\
& \text { RFM } w w s \\
& \text { 'RFM (name of a radio station)' } \\
& \text { SMS (Esse Eme Esse)PWG } \\
& \text { SMS } \quad w \quad w \quad s \\
& \text { 'id.' }
\end{aligned}
$$

$$
\begin{gathered}
\text { ??[j]/-, *-/[j] } \\
\text { PWG-level prominence } \\
\text { ??[j]/-, *-/[j] }
\end{gathered}
$$

PWG-level prominence

10. The application of $e$-deletion when followed by a stressless vowel is also (nearly) obligatory, as shown by the realization of the acronym FHM (Efe agA Eme) 'id' (name of a magazine). 
Notice that $\mathrm{V} 1$ deletion is also blocked if the acronym is in $\phi$-internal position, in which case V2 is the head of the PWG but not of $\phi$ (as in 19).

$$
\begin{aligned}
& \text { Fala-se da criação de uma TSF ??[j]/-, *-/[j] } \\
& \text { Talk-they of-the creation of a TSF } \\
& \text { (t } \hat{E} \text { Esse Efe) regional. } \\
& \text { local } \\
& \text { 'They talk about creating a local TSF (name of a radio station).' } \\
& ((t \hat{E} \text { Esse Efe)PWG (regionAl)PWG) } \phi \\
& \begin{array}{cccl}
w w & s & s & \text { PWG-level } \\
& w & s & \phi \text {-level }
\end{array}
\end{aligned}
$$

Vigário (2003a) shows, in addition, that the other processes of word-final vowel deletion argued in Frota (2000) to be sensitive to the prominence status of V2 at the levels of $\phi$ and I are also sensitive to what we now interpret as the PWG prominence. As illustrated in (20a), the deletion of word final $-a$ when followed by a non-central vowel is possible if V2 bears word-level but not $\phi$-level stress; by contrast, deletion is blocked if V2 bears $\phi$ prominence, as illustrated in (20b) (notice that in both cases $\phi$ prominence falls on the rightmost element); crucially, V1 deletion is also blocked when V2 bears the PWG stress - this is shown in (21), where - $a$ deletion is impossible because the derived word ultra-óbvio forms a PWG, the prominent syllable of which corresponds to V2.

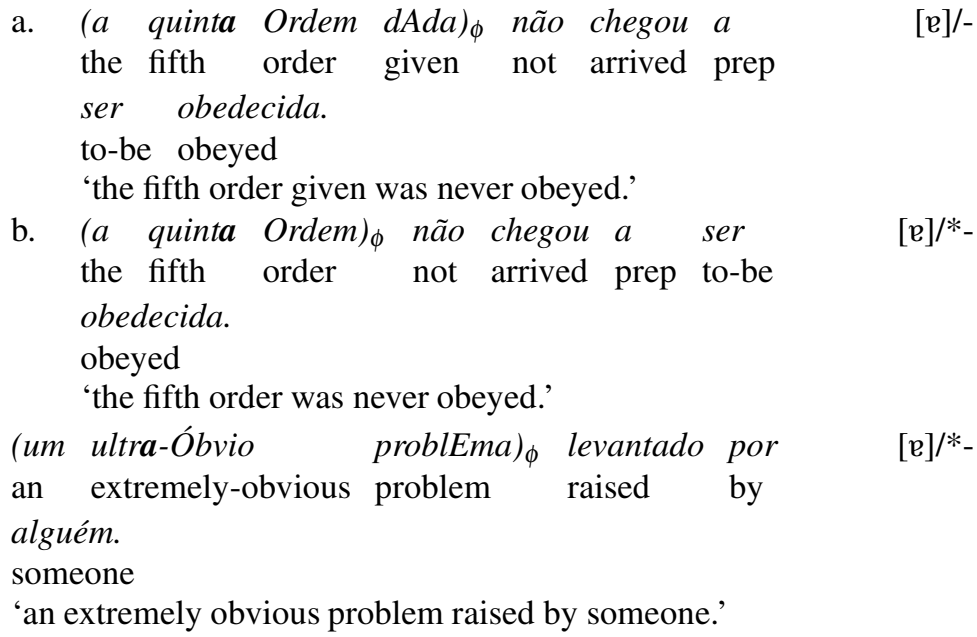

Notice that in (21) $\phi$-level stress corresponds to the rightmost PW(G) of $\phi$ (that is, problema). The prosodic configurations and prominence relations displayed by the relevant part of examples (20a) and (21) are given in (22). 
a. $((q u I n t a) \mathrm{PWG}(\text { Ordem }) \mathrm{PWG}(d A d a) \mathrm{PWG})_{\phi}$

$s$

PWG-level

$w \quad w$

$\phi$-level

b. ((Ultra-Óbvio) $\mathrm{PWG}($ prOblema $) \mathrm{PWG})_{\phi}$ w $\quad s$

A similar behavior is also found when V1 is a round vowel. In fact, although the deletion processes that affect central and round vowels exhibit some differences with respect to sensitivity to higher level prominence, the deletion of both vowels are equally blocked when V2 bears PWG stress (see Vigário 2003a: 6.2.6 for exemplification).

The third class of phonological phenomena that distinguishes sequences of words within a single PWG from those that form their own PWG within $\phi$ in European Portuguese has to do with focus assignment.

Frota (2000) shows that phonological focus in European Portuguese may be assigned not only to words that are $\phi$-final, but also to words that are non-final within $\phi$, as in (23) and (24), respectively (where we also indicate the relevant part of the prosodic structure, the specific pitch accent that associates with the head of the focused constituent, and the tonal space reduction that always follows it).

A: O artista pintou uma manhã cinzenta na sua the artist painted a morning grey on his

tela?

canvas

'Was it the gray morning that the artist painted on a canvas?'

B: (Não.) $O$ artista pintou (uma manhã no the artist painted a morning

$\hat{A}$ Mbar) $\phi$ na sua tela.

(

$\mathrm{H}^{*} \mathrm{~L}$ (tonal space reduction $\rightarrow$ )

AMBER on his canvas

'No. The artist painted an AMBER morning on a canvas.'

A: $O$ artista pintou uma tarde âmbar na sua the artist painted a afternoon amber on his

tela?

canvas

'Was it an amber afternoon that the artist painted?' 


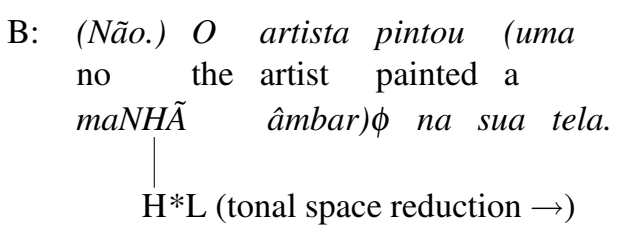

MORNING amber on his canvas

'No. The artist painted an amber MORNING on his canvas.'

Notice that there is evidence that focus does not induce a phrase boundary to the right of the focused element in European Portuguese (cf. Frota 2000, 2002).

Interestingly, the possibility of assigning focus seems to be restricted to PWs that bear the PWG prominence. This is shown in (25). Although there is strong evidence that monogâmico is formed by two PWs, only the final PW of the morphological compound may bear focal prominence. ${ }^{11}$

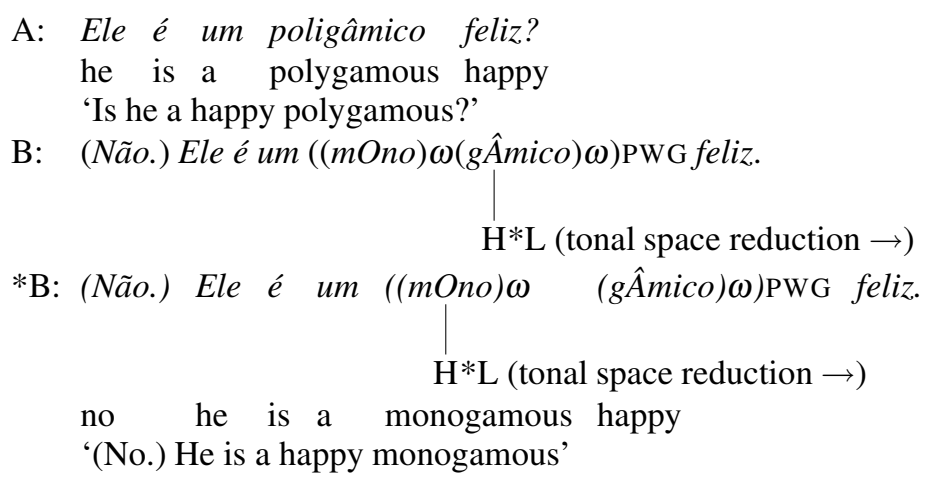

Indeed, focus cannot be assigned to the constituent that includes the first root, even though this is the element that is semantically in contrast.

To sum up, we have seen that in European Portuguese several types of phonological phenomena demonstrate the need for a phonological constituent above the PW and below $\phi$. The evidence is both segmental and suprasegmental, involving the perception of prominence, segmental processes of hiatus resolution, and prominence and tonal facts related to focus marking.

11. As said above, evidence for the PW status of the internal members of this type of morphological compound, as well as of other expressions with similar phonological behavior, is abundant in European Portuguese (Vigário 2003a: chap. 6). For example, both members of the root compound are perceived as bearing a word-level stress; the stressed vowel in the first member of the compound is not subject to vowel reduction, which affects most stressless non-high vowels in European Portuguese; and the second PW of the root compound may undergo deletion under identity (the expression monogâmico ou poligâmico may reduce to mono ou poligâmico), a phenomenon that targets $\mathrm{PW}$-level constituents and that requires that what remains in the string is also a PW (on the latter phenomenon, see also Vigário and Frota 2002) 
The constructions reported in Vigário (2003a: Chap. 6) to show evidence for a compound-like prosodic organization are the following: derived words with suffixes that bear word stress independent from the base; derived words with stressed prefixes; morphological (root+root) compounds (if not reanalyzed as simple words); morphosyntactic compounds (XP reanalyzed as $\mathrm{X}^{\mathbf{o}}$ through a regular word-formation process); a few syntactic compounds (those with a certain degree of lexicalization); mesoclitic constructions; acronyms; sequences of letter+letter (e.g., those found in car license plates); sequences of letter+numeral (used in general in the names of national roads); specific combinations of numeral+N (where factors such as high frequency of word/word combinations, together with the fact that these words belong to closed classes, seem to play a crucial role). What all these structures may have in common is that they are all dominated by a single syntactic terminal node $\left(\mathrm{X}^{\circ}\right)$, and are composed of more than one PW.

5.2.2. Compound-like constructions in English. It is well-known that a certain class of compounds in English, like in other Germanic languages, shows a stress pattern that differs from that of $\phi$. Whereas $\phi$ s usually show final prominence, compounds regularly exhibit initial stress. This is illustrated in (26), taken from Kenstowicz (1994: 550).

$$
\begin{aligned}
& \text { the téacher's ùnion } \\
& \text { the tèacher's fríend }
\end{aligned}
$$

Further examples of stress-initial compounds in English are given in (27), taken from Nespor (1999b: 138). ${ }^{12}$

$\begin{array}{lll}\text { Strong-weak pattern in } & \text { English compounds } \\ \text { Nominal compounds } & \text { bláckbird } & \text { rádio station } \\ \text { Adjectival compounds } & \text { cólorblind } & \text { séasick } \\ \text { Verbal compounds } & \text { áir condition } & \text { týpe write }\end{array}$

These facts show that in English there are certain word combinations formed of PWs which do not pattern like other sequences of PWs within $\phi$.

Interestingly, not only compounds but also some prefixed words yield a $s-$ $w$ stress pattern, as illustrated with the nouns in (28), taken from Raffelsiefen (1999).

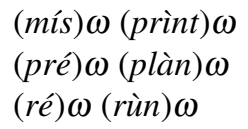

12. See also, for example, Halle and Vergnaud (1987: 7.9.3). 
Notice that, as described in detail by Raffelsiefen (1999), many prefixed words in English have non-initial primary stress and a secondary stress on the prefix. This is not necessarily problematic for our approach. In fact, although Raffelsiefen argues that in such prefixed words, the prefix forms an autonomous PW, the data she provides allows one only to conclude that the morphological base the prefix attaches to is a PW independent from the prefix (e.g., the prefix and the base form independent domains for syllabification; word initial aspiration of voiceless stops in stressed position applies even when the base is preceded by such prefixes; and glottalization and flapping also show that the material at the left edge of the morphological base behaves like PW initial elements). The facts described are thus amenable to an analysis whereby the prefix is not an autonomous PW but rather forms a syllable or a foot that is adjoined to the PW that includes the base (the adjunction of prefixes to the base PW is found in other languages as well, such as Italian and Spanish, and European Portuguese - cf. Peperkamp 1997: Chap. 3; Vigário 2003: Chap. 5, respectively; see also Booij 1995: 122 for similar data in Dutch). ${ }^{13}$

Venditti, Jun and Beckman (1996) point out that the difference in stress pattern also creates a different potential for pitch accent placement, and thus, pitch accent distribution may also contribute to distinguishing between compounds and phrases. In fact, although more than one pitch accent may be found within $\phi$ in English, according to Ladd (1996: 52) there is only one pitch accent per compound, which is associated to the compound's prominent element (in our terms, the head of the PWG). ${ }^{14}$ In other words, the PWG in this language (like in EP) seems to play a role in explaining the number and locus of association of pitch accents.

Much of these observations are also supported by production and perception experiments. In Adams (2007), the acoustic correlates of stress in English

13. Another point we should address here regards focus assignment in prefixed words. Wennerstrom (1993) claims that focus can be assigned to prefixes; according to her, this constitutes evidence for the PW status of English prefixes. However, Raffelsiefen (1999) shows that (some of) the prefixes that are argued in Wennerstrom to form independent PWs do not behave like PWs with respect to a number of diagnostics for the PW status in English. This leads her to claim that focusability is not a diagnostic for the PW. What we think explains the discrepancies in the claims regarding focusability of PWs in the two works are the different senses under which the term focus is used. In fact, the prosodic properties of English contrastive/narrow focus are not met in cases like That country has both INternal and EXternal problems (Wennerstrom 1993), where, for instance, there is no deaccenting to the right of the relevant prefixed words. Notice that similar instances of emphatic stress are found in European Portuguese (and other Romance languages) in word initial syllables irrespective of their stressed/unstressed status (cf. Vigário 2003a: 120-121 and Chap. 5). Focus is therefore not the appropriate term to use in these cases.

14. Gussenhoven (2004: 17-19) also reports that in English compounds with $s-w$ stress pattern (e.g., 'work permit'), when spoken in isolation, the first but not the second constituent of the compound is assigned pitch accent. 
compounds are specifically inspected, and a systematic comparison is made between $\mathrm{A}+\mathrm{N}$ compounds and parallel word sequences in phrases (e.g., greenhouse (for plants) and green house (residence)). Intensity, duration and pitch measurements have been taken, with the target units occurring at varying sentence locations and sentence types. Despite the fact that the acoustic correlates may vary with the prosodic environment, the results show that there are indeed acoustic cues distinguishing compounds and phrases in English. Kunter and Plag (2007) experimentally show, furthermore, that left-hand prominence is also perceived by English native speakers.

Before concluding, we should note that it is also well known that some English compounds do not bear stress on the left-hand member. We would like to claim that the distinct stress patterns observed in word compounds correlate with different syntactic structures associated to them (e.g., Liberman and Sproat 1992; Giegerich 2009). More specifically, and without going into the complex details of compound formation and classification in English, we assume that compounds formed of two prosodic words bearing left-hand stress correspond to those that are analyzed as a single syntactic terminal node $\left(\mathrm{X}^{\mathrm{o}}\right)$. Those compounds stressed on the right-hand member, however, are syntactic compounds and their internal structure is syntactically transparent, so that their internal PWs form independent PWGs and are dominated by $\phi$, like noncompound combinations of words. ${ }^{15}$ Thus, we assume that, in English, like in other languages, morphosyntactic, semantic, and/or lexical information, as

15. The need to distinguish between lexical and (post)syntactic compounds has also been claimed for Hebrew, Japanese and Dakota (see the review in Fabb 1998: Sections 4.2, 4.3 and 5.1), and phrasal compounds or lexicalized phrases have also been proposed for French (Di Sciullo and Williams 1987) and other Romance languages. In Italian, Peperkamp (1997) proposes that only $\mathrm{V}+\mathrm{N}$ compounding is productive, and the other types of compounds are considered to be listed phrases or formed via processes that are no longer productive. A similar picture obtains in EP. According to morphosyntactic criteria, the only instance of regular reanalysis of syntactic phrases as $\mathrm{X}^{\mathrm{o}}$ units in this language is also obtained in $\mathrm{V}+\mathrm{N}$ compounds (Villalva 1994). The other types of word compounds are claimed to be the result of morphosyntactic operations (in this case they exhibit some properties of syntactic terminal nodes and some phrasal properties), or correspond to lexicalized syntactic phrases (see, also Mateus et al. 2004: Chap. 24). In terms of their phonology, within word+word compounds, only $\mathrm{V}+\mathrm{N}$ regularly pattern like PWGs in EP, whereas morphosyntactic compounds and lexicalized syntactic expressions behave, in general, like other word combinations (Vigário 2003: Chap. 6). Thus, depending on their internal structure, we assume that there may be at least three types of word compounds, behaving in specific ways from a phonological point of view: compounds with internal phonological structure that is opaque (due to an unpredictable process of lexicalization), which behave like single PWs; compounds that contain more than one PW, but are under an unanalyzable syntactic terminal node $\left(\mathrm{X}^{\mathrm{o}}\right)$, which behave like a single PWG; and compounds containing more than one prosodic word, which are semantically non-compositional but that are phrasal or syntactic in nature, and behave phonologically like other combinations of words (i.e., each word corresponds to a PWG). See, also, Hualde (2006/2007) for a very similar description of Spanish compounds. 
well as, crucially, frequency of use patterns, may be required in order to determine which structures composed of more than one PW will be under a syntactic terminal node; however, once this is determined, PWGs are built and stress is assigned on a regular (phonological) basis to the initial PW of the resulting PWGs.

To sum up, English, like European Portuguese, exhibits evidence for the PWG coming from prominence patterns and pitch accent distribution.

5.2.3. Compound-like constructions in Dutch. Some Dutch compounds and derived words also display a stress pattern distinct from that of $\phi$, as illustrated in (29), taken from Booij (1995: 5.4) (where the prominence of the head and the non-head PW is marked).

$$
\begin{aligned}
& \text { Strong-weak pattern in Dutch compounds and derived words } \\
& \text { Compounds blóedplàsma 'blood plasma' } \\
& \text { jáarprèmie 'annual premium' } \\
& \text { Derived words kléurlòos 'colourless' } \\
& \text { dráagbàar 'portable' } \\
& \text { schóonhèid 'beauty' }
\end{aligned}
$$

As pointed out by Visch (1999: 3.5), Dutch nominal phrases are stress-final, whereas nominal compounds are stress-initial. Therefore, initial stress in such compounds cannot be obtained via phrasal stress assignment.

In addition to the prominence pattern, segmental rules also distinguish words within compounds from sequences of words within phrases. For instance, the rules of progressive assimilation and regressive assimilation are obligatory within words and compounds but are optional within phrases (Booij 1995; Cambier-Langeveld 2000). Progressive assimilation is a process whereby a fricative is devoiced after a voiceless obstruent, and regressive assimilation consists of the voicing of a voiceless obstruent before a following voiced stop (i.e., /b/ or /d/). The obligatory application of these processes within compounds is illustrated in (30)-(31).

(30) Progressive assimilation

$$
\begin{aligned}
& \text { opvallend 'remarkable' } \quad \mathrm{pv} \rightarrow[\mathrm{pf}] \\
& \text { afval 'trash' } \quad \mathrm{fv} \rightarrow[\mathrm{f:}] \\
& \text { stoepzout 'pavement salt' } \mathrm{pz} \rightarrow[\mathrm{ps}] \\
& \text { (31) Regressive assimilation } \\
& \begin{array}{lll}
\text { klapband } & \text { 'flat tyre' } & \mathrm{pb} \rightarrow[\mathrm{b}:] \\
\text { kookboek } & \text { 'cooking book' } & \mathrm{kb} \rightarrow[\mathrm{gb}] \\
\text { misdaad } & \text { 'crime' } & \mathrm{sd} \rightarrow[\mathrm{zd}]
\end{array}
\end{aligned}
$$

Duration facts also show a distinction between prosodic words within compounds and sequences of prosodic words within phrases in Dutch. In Cambier- 
Langeveld (2000: chap. 3), several conditions were tested to investigate what type of (prosodic) boundary blocks or attenuates the spreading of accentual lengthening to neighboring syllables. It was found that word-final unaccented syllables are part of the domain of the accentual lengthening and word boundaries have a clear attenuating effect, but, most importantly, the accentual lengthening extends to a domain larger than the stem, which must include both members of compounds. On the basis of these results, Cambier-Langeveld concludes that the domain of the accentual lengthening in Dutch coincides with the terminal element of the syntactic tree. Along the lines of this suggestion found in Cambier-Langeveld (2000: 5.3.3), we propose that the domain of the accentual lengthening in Dutch is the PWG.

Finally, evidence that PWs within compounds pattern differently from PWs within phonological phrases in Dutch also comes from speech production experiments. For instance, Wheeldon and Lahiri (2002) conducted several experiments investigating production latencies in Dutch. The question addressed was whether, in a prepared pronunciation task, compounds containing 2 PWs (e.g., ooglid 'eyelid') showed a production latency similar to adjective-noun phrases (e.g., oud lid 'old member' - 2 lexical words and $2 \mathrm{PWs),} \mathrm{or} \mathrm{to} \mathrm{morphologi-}$ cally simple words (e.g., orgel 'organ' - 1 morphosyntactic and 1 phonological word). It was found that the production latencies for compounds clearly patterned with the production latencies for morphologically simple words, rather than with the adjective-noun phrases. What we believe is the common feature of compounds and morphologically simple words is that both types of words form a single PWG. ${ }^{16}$

To summarize, different types of phenomena show that Dutch has compoundlike constructions that are formed of PWs grouped under a constituent that is distinct from $\phi$, which we propose to be the PWG.

5.2.4. Compound-like constructions in Baule. Leben and Ahoua (1997) describe the domains of several phonological rules of Baule (spoken in Côte d'Ivoire). They show that some phonological phenomena also refer to a constituent between the PW and $\phi$, which the authors analyze as a recursive PW. The evidence comes from tonal as well as segmental phenomena. In the following paragraphs we briefly review some of this evidence.

16. Again it should be noticed that the stress pattern in Dutch compounds, like in English, is not always initial (see Booij 1995: 5.4 for a list of words with internal PWs that are/are not assigned the compound stress rule and their respective morphosyntactic analysis). Like before, we assume that there is a structural difference between the two types of compounds containing more than one PW, such that only those initially stressed form an unanalyzable syntactic terminal node. 
The domain of a tonal rule whereby a sequence of High tones is realized with an upstepping pattern is reported to be the PW or specific groupings of PWs that behave differently from other sequences of words within $\phi$. This domain includes simplex lexical words, $\mathrm{N}+\mathrm{N}$ compounds, proper names, noun+numeral, as illustrated in (32a); but not combinations of words in syntactic structures such as possessor+possessed and subject+predicate (as in 32b), where upstepping is blocked.
a. Noun
Ákísí
Noun + Adjective
Compound $(\mathrm{N}+\mathrm{N})$
Proper Name
bólí kpángbán
bílí nónnón
Mómló Ámlán
bólí blú
[__--]
b. subject + predicate
Áyá bólí
possessor+possessed
bólí mángún
[_-][_-]

\author{
'Akisi' \\ 'many goats' \\ 'goat milk' \\ 'Momlo Amlan' \\ 'ten goats' \\ 'Aya is a goat' \\ 'goat's friend'
}

Upstepping may be seen to be bound by the PWG domain since its domain may include one or more PWs, which, however, do not pattern like other PWs within phrases.

Another phenomenon that refers to the same prosodic level is aphaeresis. This process optionally deletes a word initial $a$ - if the word is longer than four syllables. As illustrated in (33), two PWs within a compound are computed as a single domain for the purpose of $a$-aphaeresis, whereas the combinations of words in other syntactic constructions, such as possessor+possessed, are not.

\begin{tabular}{|c|c|c|}
\hline $\begin{array}{l}\text { Noun } \\
\frac{a k \varepsilon n d \varepsilon w a}{4 \sigma}\end{array}$ & *kendewa & 'spider' \\
\hline 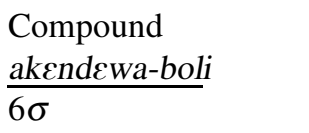 & kendewa-boli & 'spider goat' \\
\hline 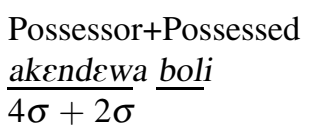 & *kendewa boli & 'spider's goat' \\
\hline
\end{tabular}

Elision is yet another process that separates PW sequences in compound-like constructions from other words under $\phi$. This process consists of the optional deletion of a word-final vowel when the following word starts with a vowel. This is illustrated in (34). 


$\begin{array}{llll}\text { Noun } & \text { Kwajo } & * \text { Kwaj } & \text { 'id.' } \\ \text { Proper name } & \text { Kwajo Aya } & \text { Kwaj Aya } & \text { 'id.' } \\ \text { Possessor+Possessed } & \text { Kwajo Aya } & * \text { Kwaj Aya } & \text { 'Kwajo's Aya' }\end{array}$

Importantly, the same domain is relevant for the three phonological processes. We propose that this domain corresponds to the PWG.

5.2.5. Compound-like constructions in Hungarian.

In Hungarian, sequences of words within compounds form a stress domain different from other words under $\phi$ (Vogel 1990). Stress falls at the beginning of non-compound words, compounds and phrases. However, compounds pattern differently from phrases, in that in compounds the stress of the second member is lost (as exemplified in 35, taken from Vogel 1990, where the stressed vowel is underlined).

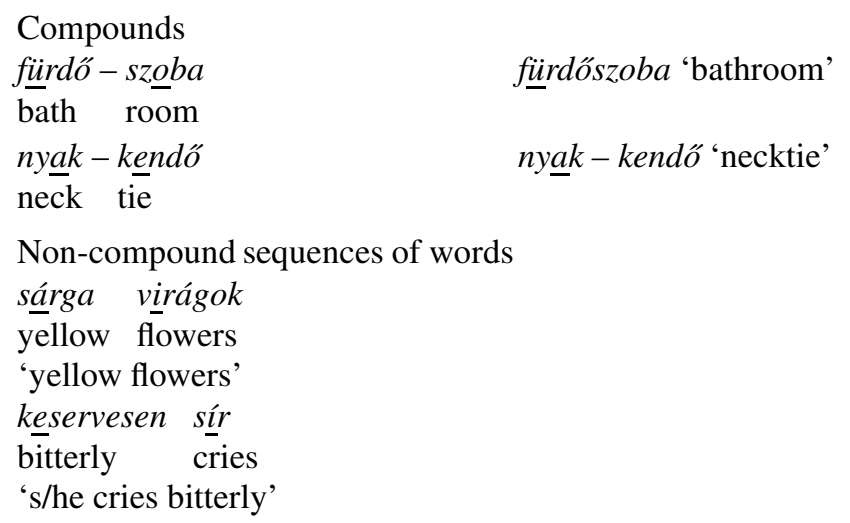

Notice that compounds also pattern differently from a non-compound word with respect to the application of several rules. For instance, the internal members of compounds form independent domains for vowel harmony (VH) and palatalization (Nespor and Vogel 1986: 4.2.2.1; Vogel 1990). The application of $\mathrm{VH}$ within the PW, but not across the member of compounds is exemplified in (36), taken from Nespor and Vogel (1986: 4.2.2.1) (the vowels that undergo $\mathrm{VH}$ are marked with boldface).

(36) Non-compound words

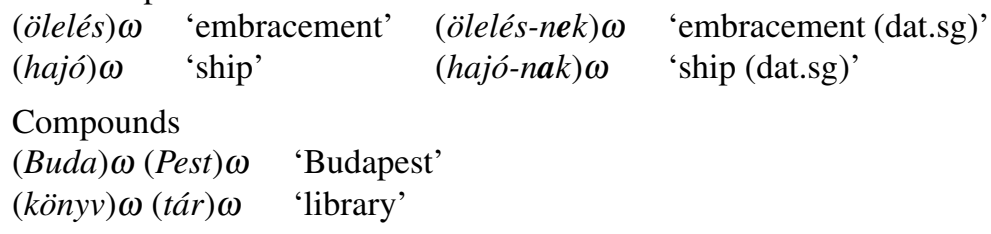


The fact that compounds form a distinct domain from both the PW and $\phi$ means that a constituent between these two domains is required. Vogel (1990) proposes that this constituent is the clitic group. For the reasons stated before, we reinterpret that constituent as the PWG.

5.2.6. Compound-like constructions in Warlpiri. A very similar picture is found in Warlpiri. In this language, the prosodic word is a domain for stress and vowel harmony (Nash 1986; Pentland and Laughren 2004) ${ }^{17}$. The PW is also a domain of phonotactic constraints - for example, a PW in Warlpiri must contain at least two moras, and begin with a consonant and end with a vowel (Pentland and Laughren 2004: Note 2).

Prominence and vowel harmony $(\mathrm{VH})$ provide evidence for the need of considering two distinct prosodic levels of prosodic constituency around the prosodic word level.

The example in (37), illustrates compound stress in a preverb-verb complex, formed of two prosodic words, each of which has its own primary stress. As it can be seen, like in other languages reviewed here, the compound defines a separate domain for prominence, since the first prosodic word is more prominent than the second prosodic word within the compound.

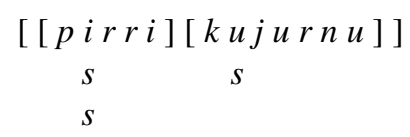

As for $\mathrm{VH}$, like in Hungarian, it applies within prosodic words, but not across prosodic words within compounds.

This process consists of the regressive assimilation of $/ \mathrm{i} / \mathrm{to} / \mathrm{u} /$, which is triggered by the $[+$ back, +high] vowel of the PAST suffix (see 38).

$$
\begin{array}{ll}
\text { kiji-rni } & \text { 'throw-NONPAST' } \\
\text { kiji-ka } & \text { 'throw-IMPERATIVE' } \\
\text { kuj } \underline{u}-r n \underline{u} & \text { 'throw-PAST' }
\end{array}
$$

As illustrated in (39), VH does not extend past the verb root into a preverb (Nash 1986; Pentland \& Laughren 2004).

$$
\begin{aligned}
& \text { pirri-kuju-rnu } \\
& \text { *purru-kuju-rnu }
\end{aligned}
$$

17. In our description of Warlpiri, essentially based on Pentland and Laughren (2004), we reinterpret the facts in light of our proposal, using the labels PW and PWG, where these authors use prosodic word and phonological word, respectively (see also Note 18 below). 
These facts may be accounted for if it is assumed that the domain for vowel harmony is what we call the PW, and the node that dominates the preverb-verb complex is the PWG. ${ }^{18}$

5.2.7. Compound-like constructions in French. Hannahs (1995b) also finds evidence for this level of prosodic hierarchy in French compounds. The evidence comes from penultimate schwa specification. In this language, schwa is specified, and thus obligatorily realized, in the final position of the penultimate foot of a word, including compounds and non-compounds, as shown in the examples in (40), below.

$$
\begin{array}{lll}
\text { a. fermeté } & \text { [ferməte] } & \text { 'firmness' } \\
\text { b. porte-clés } & \text { [portəkle] } & \text { 'key ring' }
\end{array}
$$

The vowel becomes optional in non-compound word sequences, as in (41).

$$
\begin{array}{ll}
\text { bourc }(e) \text { pleine } & \text { 'full purse' } \\
\text { Georg }(e) \text { s dit } & \text { 'Georges says' }
\end{array}
$$

Notice that there is also evidence that compounds do not form a single PW. In fact, each member of a compound behaves as a separate domain with respect to phenomena such as glide formation and closed syllable adjustment, which are shown to have the PW as domain (see Hannahs 1995b for the details).

In conclusion, compounds in French behave differently from both single PWs and from phrasal word combinations. Under our analysis, compounds are formed of more than one PW grouped under a single PWG.

5.2.8. Compound-like constructions in Korean and Japanese. Venditti, Jun and Beckman (1996) observe that in Korean and Japanese there is a distinction in the accentual phrasing of syntactic phrases and of compounds. As exemplified in (42) with Korean data, taken from Venditti, Jun and Beckman (1996: 297), two words inside a compound form a single accentual phrase (AP) (in the authors' terms), whereas they form separate APs when part of a syntactic phrase.

18. Pentland and Laughren (2004) explain these facts establishing a difference between the prosodic word and the phonological word. These are meant to be two distinct prosodic domains, each of which defines the domain of different types of phenomena, segmental and suprasegmental. As we show in this article, an alternative analysis is available, which has the advantage of being suitable for many other languages. Notice, furthermore, that segmental and suprasegmental phenomena are found both at the level of the PW and the PWG in many languages. Besides that, we should also point out that, according to Nash (1986), as also mentioned in Pentland and Laughren's article, both the internal members of compounds and the compound as a whole form domains for stress assignment. Therefore, it does not seem possible to say that prominence is a property of only one of the levels under consideration. 


\title{
514 Marina Vigário
}

\author{
$(42)$

$\begin{array}{ll}\left(\text { t } \int a k i n \text { tip }\right) \mathrm{AP} & \text { 'younger brother's family' } \\ (\text { t fakin }) \text { AP (tip)AP } & \text { 'small house' }\end{array}$

Notice that APs in Korean and Japanese are tonally demarcated at the beginning and the end of the phrase (Jun 2005a; Venditti 2005, respectively). According to Ito and Mester $(2006,2007)$, furthermore, (some) Japanese compounds display deaccenting and the presence of a junctural accent, occurring on the first syllable of the second member and replacing the lexical accent of the second member or being added to it if the second member is lexically unaccented.

A full treatment of the prosodic structures displayed by Japanese or Korean compounds is beyond the scope of this article. ${ }^{19}$ Despite the complex issues involved in the phonology of compounds in these languages, we believe that the facts just reported are clear in suggesting the need to consider a level of prosodic grouping in Japanese and Korean that is lower than that displayed by words combined within syntactic phrases. In our terms, the PWs inside compounds may be seen to form a single PWG, whereas in phrases, each PW forms its own PWG. ${ }^{20}$

19. Ito and Mester $(2006,2007)$ suggest that besides deaccenting and the junctural accent, Rendaku (compound voicing) is also a cue to the specific prosodic structure of compounds in Japanese, since when Rendaku is present, deaccenting also occurs. They notice, however, that deaccenting does not necessarily imply the presence of Rendaku. This is seen to support a four-way distinction in the prosodic structure of Japanese compounds, which Ito and Mester derive resorting to two basic categories (the PW and $\phi$ ) and different levels of adjunction structures to these two basic domains. Our understanding of the data presented is different, however. In fact, we believe that Rendaku must be considered a lexical phenomenon, since its presence only occurs when non-initial members of compounds are native lexical items. This means that the absence of Rendaku in some of the compounds that trigger deaccenting may be due to lexically marked exceptions. Accent distribution, by contrast, seems to be purely phonological and without exception, and thus it may be used as a reliable diagnostic for the prosodization of compounds. Assuming this, we can account for the whole range of data described in Ito and Mester's work: left-branching compounds have maximally one accent, located on the head, which corresponds to the second member; in our account, these compounds (regularly) form a PWG; right-branching compounds are phrasal (or syntactic) compounds and therefore do not form a single PWG (like similar objects in Portuguese, English or Dutch, as seen above). This explains why they do not display the deaccenting pattern. However, like in other languages, some phrasal compounds may lexicalize and become prosodically similar to word compounds. In this case, they display the deaccenting pattern. Here, Rendaku may be found, and this may be one of the features showing that a phrasal compound has lexicalized.

20. For space limitations, it is not possible to discuss here the extent to which there is a coincidence between the AP and the constituent we are proposing. We should at least point out that the AP is characterized in Jun (2005b) as 'a small unit above the Word', usually formed of a single PW - according to Jun (2005b), Korean APs contain on average 1.2 content words, and 3-4 syllables. Additionally, S.-A. Jun (personal communication) confirms what can already be extracted from an inspection of the data in the literature on Korean, which is that APs 
5.2.9. Compound-like constructions in other languages. Many other languages show evidence for a separate constituent between what the PW and $\phi$. These include Arrernt (Henderson 2002), Bantu languages (Downing 1999 ${ }^{21}$ ), Basque (Hualde, Elordieta and Elordieta 1994), Bengali (Hayes and Lahiri 1991), German (e.g., Wiese 1996), Icelandic (Árnason 1999), Irish (Green 2008), Shanghai Chinese (Selkirk and Shen 1991; Duanmu 1991), Swedish (e.g., Bruce and Hermans 1999; see also 5.3 below), and Turkish (Kabak and Vogel 2001; see also 5.3 below), among others. ${ }^{22}$ For space limitations, we cannot survey all the facts here. However, the data of some of these languages is reviewed in the following section, where we crucially argue against recursive PWs.

\subsection{Evidence against recursive prosodic words}

Following Nespor and Vogel (1986/2007), Pinker and Jackendoff (2005), Vogel (2009), among many others, we assume that recursion is not a fundamental property of phonology (but of syntax). However, we should stress that this is ultimately an empirical issue. In this section, we aim at adding evidence against the analysis of the prosodization of compound-like constructions resorting to recursive prosodic structures.

The first argument against recursive structures and in favor of the PWG comes from what is to be expected from recursive structures. It seems uncontroversial and intuitive that in this type of construct the lower and the higher node should have the same properties (e.g., Ladd 1996: 6.3.2; Frota 2000, to

containing more than one content word are usually composed of compounds or very frequent word combinations, like for instance what happens with European Portuguese PWGs. Jun (2005b) suggests that the AP coincides with $\phi$ in other prosodic typologies. What we show in this article is that in several languages, three levels of phrasing are needed above the PW, since PWGs pattern differently from $\phi$ s, and $\phi$ s pattern differently from Is (e.g., Frota 2000 and subsequent work; Vigário 1998, 2003b, for European Portuguese). In fact, based on evidence from sentence processing showing attachment preferences, Jun (2007) claims that an intermediate level between AP and I is also needed in Korean (the term adopted there is the intermediate phrase). For all these reasons, it seems to us that the AP is better equated with a constituent lower than $\phi$. Similarly, a coincidence may exist between (at least some uses of) the minor phrase and the PWG we are proposing (e.g., Selkirk, Shinya and Kawahara 2004).

21. We believe that what Downing (1999) calls the prosodic stem and the prosodic word may readily be reinterpreted as our PW and PWG, respectively. The advantage of this reinterpretation is that the same prosodic hierarchy may be posited for Bantu and other languages.

22. Polysynthetic languages, such as Cree and Dakota, may possibly be added to this list. Russell (1999) shows that several internal parts of complex words in Cree and Dakota form independent prosodic words. He suggests that these prosodic words are directly attached to the phonological phrase. We believe, however, that the constituent may in fact correspond to our PWG. Such an analysis would allow for the word, in a morphosyntactic sense, to correspond in general to a PWG, like in all other languages discussed in this article. 


\section{Marina Vigário}

appear). Given this assumption, there is one specific type of phenomenon that is particularly suited to test whether the groupings of words we are considering are best accounted for via recursive structures or by means of a proper prosodic constituent. The relevant phenomenon is prominence assignment. In fact, the two approaches under evaluation make different predictions with respect to the stress patterns that can be found in compound-like constructions crosslinguistically: the analysis involving recursive structures implies that there should always be a coincidence between the stress pattern found at the wordlevel and within recursive PWs; by contrast, if the PW and the PWG are two distinct prosodic domains, this coincidence is not required; in this case, it is expected that in some languages the two levels will have the same stress pattern (like PWs and $\phi$ s in all Romance languages), whereas in others the two levels will display distinct stress patterns (like PWs and $\phi$ s in languages like Icelandic or Turkish - see Árnason 1999; Kabak and Vogel 2001, respectively).

Several languages provide the required evidence against recursion. Here we review data from Turkish, English, Dutch and Swedish.

We shall start with Turkish. In this language, word stress is assigned with reference to the right-edge of the PW (cf. Nespor and Vogel 1986: 4.2.1.2; Kabak and Vogel 2001). However, in compounds and in other specific combinations of words, the main stress corresponds to the leftmost PW (see 43, taken from Kabak and Vogel 2001).

$$
\begin{array}{ll}
\left(\text { kará }_{\omega}\right. & \text { 'black } \\
\left(\text { deníz }_{\omega}\right. & \text { 'sea' } \\
\left(\text { kará }_{\omega}\left(\text { deniz }_{\omega}\right)\right)^{\text {'the Black Sea' }} &
\end{array}
$$

In Turkish, therefore, the stress of compound-like constructions is not obtained via the application of the word stress rule to the higher (recursive) PW. The data can be accounted for if we admit, instead, that the PW and the PWG constitute two distinct levels of prominence, assigned by two distinct rules.

We should notice that the whole structure also behaves differently from PWs (forming an independent PWG) directly dominated by $\phi$. In fact, according to Kabak and Vogel (2001), although $\phi$-stress is also initial, a PW at the right of $\phi$ keeps what seems to be the word-level stress, unlike when it is part of a compound-like expression, in which case its stress is reduced (see also Lees 1961, cited in Nespor and Vogel 1986). This motivates the grouping of the members of the compound within a constituent distinct from $\phi$ (in Kabak and Vogel's terms, the clitic group).

The minimal pairs in (44), taken from Kabak and Vogel (2001), illustrate the distinction between compounds and phrases (in 44 we substitute the CG in the original example by the PWG). 
(44) Non-compound

$$
\begin{array}{ll}
\left.\left((\text { süt })_{\omega}\right) \mathrm{PWG}\left((\text { beyáz })_{\omega}-\text { dir }\right) \mathrm{PWG}\right)_{\phi} & \text { 'milk is white' } \\
\text { Compound } & \text { 'it is milk-white' } \\
\left(\left((\text { süt })_{\omega}(\text { beyaz })_{\omega}-d i r\right) \mathrm{PWG}\right)_{\phi} &
\end{array}
$$

To conclude, it is important to note that besides stress facts, Turkish syllabification rules also cue this specific domain. According to Kabak and Vogel, syllables consisting of more than two moras are ill-formed and therefore, when they occur, some rules must apply to avoid them. For instance, an extra consonant in syllable final position may be preserved if it is followed be a vowelinitial morpheme that allows it to function as an onset. However, this may only happen within clitic (or, in our terms, prosodic word) groups, not across words within $\phi$

As we have seen above, English and Dutch, like Turkish, also show a stress pattern in compound-like constructions that is distinct from that found in noncompound word combinations.

Word-stress is assigned currently in both languages with reference to the right-edge of the word (e.g., Halle and Vergnaud 1987: Chap. 7 for English; van der Hulst, Hendriks and van de Weijer 1999 for both English and Dutch). Examples from English word-level right-hand stress are given under (45), taken from Halle and Vergnaud (1987: 228).

\section{onomatopéia hamamelidánthemum}

Whereas compounds with final-stress may be seen as phrasal or syntactic compounds, thus showing $\phi$ stress pattern, the stress pattern of initial-stress compounds like bláckbird, séasick or áir condition (cited above) cannot be accounted for by the general rules that assign stress at the word-level. ${ }^{23}$ Like in the Turkish case, in our view, this points against the treatment of these forms as involving recursive PWs.

23. Multi-word compounds may be seen to have an internal structure that correlates with their interpretation and with their prosodic organization and stress distribution. As in other levels of prosodic hierarchy, prosodic phrasing may also be used as a cue to different syntactic organizations of the compound's internal members. For example, a compound like American history teacher may be assigned two structures, $[\mathrm{N}+\mathrm{N}-$ poss $]+\mathrm{N}-$ poss and $\mathrm{N}-$ poss $+[\mathrm{N}+\mathrm{N}-$ poss $]$, correlating with two different prosodic markings (Fabb 1998). As far as we can see, there is no compelling reason to assume that multi-word compounds such as these display recursive PWGs. Instead, we would like to suggest that these are phrasal, syntactic compounds that may include lexical compounds - only the internal elements of this type will be grouped inside a single PWG and thus trigger initial stress; being phrasal, each of the remaining words behaves like other words within phrases, forming a PWG on their own. This may explain why in some cases it seems that we may find prominence assigned to an internal PW within a compound, like in American hístory teacher (Fabb 1998: 79). Thus, under our proposal the stress pattern of sequences like these at the level of PWG is in fact (Américan)PWG (hístory teacher)PWG. 
A similar picture emerges in Swedish, where according to Bruce and Hermans (1999) non-compound word stress pattern is right-hand dominant (this stress pattern is found in simplex words and certain derivatives, in lexicalized phrases and certain compound words). In compound-like expressions, by contrast, stress is left-hand dominant, with the main stress on the first element (according to Bruce and Hermans, this stress pattern is found in real compound words and certain derivatives, like adjectives ending in - $i v$, in formal compounds, certain enclitic constructions and certain non-compound words).

Notice that there are additional pieces of evidence for a specific prosodization of compound-like expressions in Swedish, distinct from both the PW and $\phi$. First, syllabification facts, stop devoicing and geminate reduction show that the internal members of compounds, as well as some suffixes, form their own PW (Bailey 1988). For example, geminate clusters reduce across words within compounds, unlike in non-compound sequences of words - see (46) (taken from Bailey 1988: 5.4, citing Eliasson 1986).

$$
\begin{aligned}
& \text { Compound } \\
& / f \text { akk klubb/ } \rightarrow \text { [fak:leb:] } \\
& \text { Non-compound word sequence } \\
& / \text { dansk klubb/ } \rightarrow \text { [dansk kleb:] 'Danish club' }
\end{aligned}
$$

In addition, according to Bailey (1988) compounds receive only one accent, unlike sequences of words within $\phi$, where each PW receives an accent (like, for instance, in English). Furthermore, similar to European Portuguese and English, in Swedish the compound as a whole functions as the unit of focus, since the focusing of an internal element is not allowed (Bruce and Hermans 1999: 611; see also Gussenhoven and Bruce 1999: 4.3.1 on the placement of the focal tone in Swedish).

In our view, the facts just reviewed point to a specific prosodization of compound-like expressions in Swedish, which appear to be grouped within a constituent between the PW and $\phi$. Similar to Turkish, English and Dutch, the fact that the stress pattern at the level of the PW and that at the level of compound-like word combinations in Swedish are reversed seems to us to constitute clear-cut evidence against recursive PWs, and thus to strongly argue in favor of the existence of a proper domain between the PW and $\phi$.

A second type of argument against the analysis resorting to recursive structures also springs from what should characterize recursive as opposed to nonrecursive domains. Compound (recursive) prosodic domains have been proposed to display a difference in strength with respect to the internal constituents, but not a difference in kind (cf. Ladd 1996/2008; Frota 2000²4). As Frota (to

24. For example, Frota (2000) proposes that compounding at the level of I is allowed in EP, 
appear: Section 2) puts it "recursion and compounding refer to forms of grouping of instances of a given prosodic category, yielding levels of phrasing that are reflected only by gradient differences in the strength of the same phonetic properties."

In contrast with this characterization, we often find categorical, obligatory, non-gradient facts distinguishing between the PW and the PWG. Among the examples that could be cited here, we may refer to vowel harmony in Hungarian and Warlpiri, which only applies within PWs but not across PWs within a compound, or the examples mentioned above where two distinct (categorical) rules assign stress at the level of PW and at the level of PWG. This strongly suggests that we are in presence of two distinct prosodic domains, instead of different layers of the same prosodic category. In our view, this is an important argument since it bears on a distinction that must be made between proper prosodic domains and compound prosodic domains. In the absence of clear diagnostics for both types of structures, the theory of prosodic structure is weakened.

Another reason to prefer PWGs over recursive PWs also regards the strength of prosodic theory. As can already be largely inferred from the facts shown in this article, the PWG has all the properties that have been attributed to the prosodic constituents classically assumed. We review some of the relevant facts in the following paragraphs, and also bring some new data bearing on the issue.

First, several types of (pure) phonological phenomena cue the PWG in particular languages: we have seen that more than one type of phenomena - segmental, tonal, durational, and prominence related - cue the PWG in many of the languages reviewed in this article.

Second, the type of information used in the construction of the PWG is similar in many languages of the world, as well as the point in the grammar where the interface is established with other components of the grammar: the PWG seems to establish an interface with syntax at the $X^{\circ}$ level (see Section 5.4), in the same way as $\phi$ establishes an interface with syntax at the XP level, (e.g., Nespor and Vogel 1986/2007; Frota 2000; Selkirk 2000; Truckenbrodt 2007).

Third, like for the other prosodic domains, the evidence for the PWG is found in many languages of the world.

It is well-known that prosodic domains are often constrained by size requirements (e.g., Nespor and Vogel 1986/2007; Ghini 1993; Selkirk 2000; Frota 2000; Frota, D’Imperio, Elordieta, Prieto and Vigário 2007) - for example, IPs tend to have a certain maximum and minimum size, degenerate $\phi$ s tend to

where $\mathrm{I}^{\mathrm{min}}$ boundary displays the same general properties as $\mathrm{I}^{\mathrm{max}}$, such as being assigned nuclear pitch accents and boundary tones, and displaying temporal boundary marking, but the two exhibit boundary strength contrasts, manifested by preboundary lengthening, pitch range extension and pause distribution differences. 
group with the preceding $\phi$, and PWs very often have minimality requirements. Also in this respect the PWG seems to pattern like other prosodic domains. Two sets of data, coming from Baule and European Portuguese, illustrate this point. As we have seen in Section 5.2.4, in Baule there is a tonal rule whereby a sequence of High tones is realized with an upstepping pattern; we have argued that the domain for this rule is the PWG since only simplex words, and certain specific combinations of PWs trigger the rule $(\mathrm{N}+\mathrm{N}$ compounds, proper names, noun+numeral), but not combinations of words in syntactic structures such as possessor+possessed and subject+predicate. Interestingly, what would otherwise form an independent PWG is grouped with the previous PWG when composed of a single syllable (see Leben and Ahoua 1997), thus suggesting minimality restrictions at the PWG level. Thus, for example, two adjacent PWs bearing a possessor+possessed relationship, will yield the upstepping pattern if the second PW is monosyllabic, as in (47).

$$
\begin{aligned}
& \text { Possessor+possessed } \\
& \text { bólí tí } \\
& \text { [-- }- \text { ' }]
\end{aligned}
$$

In Portuguese the PWG also shows size restrictions, as PWGs containing four PWs are separated in two PWGs, as in the examples in (48).

$$
\begin{aligned}
& (M R)(P P) \quad \text { 'party name acronym' } \\
& (B B)(V A) \quad \text { 'bank name acronym' }
\end{aligned}
$$

Besides perception and intuition, evidence for the groupings in (48) comes from the behavior of $-e$ deletion in prosodic word-final position. As we have seen in Section 5.2.1, the deletion of a stressless $-e$ is (nearly) obligatory in PW-final position; however, deletion is blocked when the vowel is followed by a word starting with a vowel that bears PWG stress. In example (49), where the acronym includes four PWs, we see that deletion is blocked between the first and the second PW, thus showing that the second PW is the head of its PWG; the example in (50) shows that acronyms with three PWs are not broken into smaller PWGs (since the blocking of $-e$ deletion is only triggered by the stressed vowel of the last PW, the head of the ternary PWG, but not by the stressed vowel of the second PW). The evidence thus clearly points to the preference for binary PWG in EP, and the avoidance of degenerate PWGs. ${ }^{25}$

$$
\begin{array}{ll}
(M R)(P P) & \quad \text { 'MRPP (a political party)' } \\
& \operatorname{Em}[\mathrm{j}] \text { Erre } \mathrm{p} \hat{\mathrm{E}} \mathrm{p} \\
w \quad s \quad w s &
\end{array}
$$

25. We should notice that there is no evidence that the two binary PWGs inside the acronym form a prosodic constituent. Thus, we propose that each PWG is directly attached to $\phi$. 
The fifth property that PWGs share with other constituents of prosodic hierarchy has to do with the existence of groupings that are not isomorphic to the morphosyntactic constituents. As we have just seen, PWGs may be subject to size restrictions. The need to satisfy size constraints may cause the separation of the elements under a single syntactic head into more than one PWG (as in the EP data mentioned above), or the inclusion of the elements under two syntactic heads in a single PWG (as in Baule).

The final property we would like to mention here showing that the PWG behaves like other prosodic domains is the fact that it is a domain for prominence, as data from many languages reviewed in this article have shown.

Since the definition of the domains belonging to the prosodic hierarchy is grounded on the existence of those properties, only acknowledging the PWG preserves the foundations of the theory of prosodic structure.

To sum up, we hope to have shown that there are several types of problems that are created if we analyze the relevant linguistic data resorting to recursive prosodic words. These problems disappear once we admit the existence of a prosodic domain of its own right between the $\mathrm{PW}$ and $\phi$, which we call the PWG.

\subsection{On the construction of the PWG}

It is not our purpose to develop here a complete theory of the formation of PWGs. We will nevertheless present some notes on how the formation of the PWG should obtain.

From what we have seen, the structures containing PWs that are grouped within a single PWG usually involve words that are syntactic (lexical) terminal nodes $\left(\mathrm{X}^{\circ}\right)$. Given this observation, we may account for the basic facts using tools widely accepted within Optimality Theory framework. In particular, we may account for the coincidence most often observed between the edges of $\mathrm{X}^{\circ}$ and the edges of the PWG resorting to classical alignment constraints (McCarthy and Prince 1994; Selkirk 1996), stating that the right and left edges of $\mathrm{X}^{\mathrm{o}}$ - a syntactic terminal node, not necessarily coinciding with the morphological word - must coincide with the right and left edges of the PWG, respectively. ${ }^{26}$ Besides that, a constraint of the WRAP family at the level of $\mathrm{X}^{\circ}$ $\left(\mathrm{WRAP}-\mathrm{X}^{\mathrm{o}}\right)$, requiring that each $\mathrm{X}^{\mathrm{o}}$ is contained in a PWG, may also play a role

26. Selkirk (1996) proposes that Prosodic Word Alignment Constraints require that the edges of $\mathrm{X}^{\mathrm{o}}$ must coincide with the edges of PWs. We are assuming, instead, that the level of prosodic 
in the formation of the PWG, preventing the material under $\mathrm{X}^{\circ}$ from being split into several PWGs (see Truckenbrodt 1995, 1999; Peperkamp 1997; Selkirk 2000; among others, for the role played by constraints of this family in several languages and at several morphosyntactic levels). ${ }^{27}$

The constraints above are capable of accounting for the fact that a variety of morphosyntactic objects that are formed of more than one PW behave like a PWG. These objects include some prefixed words (as in Dutch, Swedish, or EP), some suffixed words (as in Dutch or EP), certain compounds, other than phrasal or syntactic compounds (as in Baule, Dutch, French, English, EP, Hungarian, Swedish, Shanghai Chinese, and many other languages), Warlpiri's preverb-verb complex, and also EP mesoclitic constructions, a particular verbal construction formed of an old auxiliary+verb complex that has undergone a (partial) lexicalization process (the auxiliary has lost its syntactic independence, having become a bound element, while maintaining its prosodic word status). ${ }^{28}$ Combinations of letters, as those in acronyms or in license plates, and combinations of letters and numerals, as in the names of roads (e.g., N1 'national road 1') also regularly form a branching PWG in EP.

We have also seen in the preceding subsection that languages may impose a minimum or a maximum size for PWGs. Thus, size constraints must also come into play in the formation of the PWG. In a language like EP, where an $\mathrm{X}^{\mathrm{o}}$ that includes more than three PWs must be split into two PWGs (as in the examples with acronyms presented earlier), we may account for the violation of WRAP- $\mathrm{X}^{\mathbf{o}}$, assuming that this constraint is ranked lower than the one defining the maximum size of PWGs. ${ }^{29}$

hierarchy that relates to $\mathrm{X}^{\mathrm{o}}$ is the PWG and not the PW. In fact, it is possible that the level that best relates to the PW is (only) the stem. For instance, in languages like Italian or Spanish (or EP) it is clear that alignment constraints at the level of PW require that the left edge of stems (not necessarily coinciding with the left edge of $\mathrm{X}^{\mathrm{o}}$, like in the case of prefixed words) coincides with the left edge of the PW (see, in particular, Peperkamp 1997: chap. 2, and the references therein). This is also the case for other languages, like Sanskrit, Turkish and Hungarian (see relevant data in Nespor and Vogel 1986: 4.2), as well as for the Bantu languages whose data are reviewed in Downing (1999), leading the author to propose a distinction between prosodic stems and prosodic words, corresponding, in our terms, to PWs and the PWGs (see also McCarthy and Prince 1994: section 5).

27. See also Kabak and Revithiadou (2009) for a very similar phonological analysis of compoundlike constructions in Turkish, although deriving recursive PWs instead of PWGs.

28. See Vigário (2003a: Chap. 3 and 6) for the phonological and syntactic analysis of mesoclisis in EP.

29. Highly frequent combinations of words, such as those including numerals plus the words horas 'hours/o'clock' and anos 'years', and also the newly introduced euros 'euro' (European Union's currency since 2002) behave phonologically like a single PWG in EP as well (see Vigário 2003a: chap. 6 for relevant exemplification). This means that frequency information must also be taken into account in order to understand the behavior of the PWG in Portuguese, as well as in the other languages. We should stress that frequency effects of this sort are also observed at other levels of grammar and may explain some of the unexpected behavior found 
As said above, it is beyond the scope of the present article to provide a full account of the conditions under which the PWG obtains. We will thus leave the topic for future work.

\section{Concluding remarks}

In this article, we have argued that a prosodic constituent is needed between the PW and $\phi$. We have seen that there are strong arguments against the clitic group, a constituent of the same level, which already existed in early work on prosodic phonology (e.g., Nespor and Vogel 1986; Hayes 1989; Vogel 1990). However, we have noticed that the compelling reasons to abandon the clitic group only involve clitic-host combinations, not compounds. This has motivated our proposal that a new name should be given to a domain of this level, which we propose to be prosodic word group (PWG).

In order to support the need for the PWG, we have collected various types of phenomena showing that compound-like structures form a domain for the application of pure (regular) phonological rules in many languages, belonging to various language families (namely, Baule, Dutch, English, European Portuguese, French, Hungarian, Japanese, Korean, Swedish, Turkish, and Warlpiri), and other languages were additionally reported to also show potential evidence for this level of prosodic constituency (including Arrernt, Basque, Bengali, Bantu languages, German, Icelandic, Irish, and Shanghai Chinese).

We have also presented evidence against the alternative analysis involving recursive PWs. It was shown that in some languages the rule that assigns prominence at the level of the PW is the reverse from that assigning prominence at the level of the prosodic domain that groups compound-like expressions. In our perspective, this cannot be accounted for under an analysis involving recursive nodes, because here the properties of the lower PWs are crucially expected to also characterize the higher (recursive) PW. Examples have also been given of phenomena showing that the difference between the PW and the PWG is not one of strength, but one of kind, thus suggesting that recursive, compound prosodic words are not viable alternatives to the PWG. Finally, we have pointed out that the evidence in favor of the PWG is precisely of the same type as that used for supporting the other prosodic domains, and thus only the adoption of the PWG is compatible with the theory of prosodic structure.

The analysis presented here also has the advantage of eliminating an important source of violation of *Recursivity, a constraint that is crucial for a basic

related to prosodic organization. For example, Peperkamp (1997: Chap. 4) proposes that the high frequency of use may also be involved in the loss of the PW status of the first member of some word compounds in Italian, and she proposes a constraint of the WRAP-family to account for these cases. 
distinction between prosodic and syntactic structures (the former being flatter and limited, the latter being deeper and potentially unlimited).

An issue that should be explored in the future is whether balanced recursivity (where a node $\mathrm{X}$ dominates two constituents of the same level $\mathrm{X}$ ) can be excluded from phonology. At this point, we believe it can. That does not mean, nevertheless, that compound domains do not exist. We have seen that there is phonetic evidence suggesting that these groupings do exist, at least at the intonational phrase level (see Ladd 1992, 1996/2008; Frota 2000; among others). However, as we have seen, compound domains trigger gradual distinctions, and thus may be seen to be phonetic rather than phonological in nature. Under this view, it seems to be possible to exclude balanced recursivity from phonology.

As for how the formation of a complex PWG is obtained, we have seen that the constructions containing PWs that are grouped within a single PWG usually involve lexical units that are syntactically dominated by a single $\mathrm{X}^{\mathrm{o}}$. Given this observation, and assuming the Optimality Theory framework developed by McCarthy and Prince (1994) (also of Selkirk 1996, 2000; Truckenbrodt 1995, 1999; Peperkamp 1997; among many others, for other levels), we have proposed that constraints of three major types may capture the general properties of PWGs: alignment constraints, defining that the left and the right edges of (lexical) $\mathrm{X}^{\mathrm{o}}$ coincide with the left and right edges of PWGs, respectively; WRAP- $X^{\circ}$, preventing $X^{\circ}$ from being split into two or more PWGs; and sizeconstraints, defining PWGs minimum and maximum sizes.

It also follows from the facts presented in this article, that the PWG (or a constituent of this prosodic level) is not confined to the prosodization of compounds. In fact, constructions that are formed of two PWs grouped in a constituent distinct from $\phi$ may also involve other types of words or word combinations. Evidence for this can be found in languages like European Portuguese, Dutch, Swedish, Turkish, Icelandic, and Warlpiri, where besides (some) compounds, also some derived words, and other types of morphosyntactic objects display parallel phonology. Similarly, not all compounds are formed from two or more PWs that are grouped under a PWG, a fact that most probably results from the distinct morphosyntactic organization of the different types of compounds.

To conclude, a very interesting research topic that follows from the present proposal concerns the role that the PWG may play in language acquisition. In languages where compounding is not productive (for example, Arabic), PWs and PWGs will possibly most often coincide, whereas this will not happen in languages where compounding and other morphological processes creating words with internal PWs are quite productive (such as, Chinese, or Bantu languages, respectively); and in languages with more complex morphology, like many polysynthetic Amerindian or Australian languages, several PWs will possibly be often found within a PWG. The hypothesis may then be raised that 
these differences at the PWG level may play a role in the bootstrapping of important morphosyntactic properties of the languages to be acquired. The exploration of this line of investigation is left open for future work.

Universidade de Lisboa marina.vigario@mail.telepac.pt

\section{References}

Adams, Tuuli Morrill. 2007. Phonetic cues identifying English compounds. In Jürgen Trouvain \& William J. Barry (eds.), Proceedings of the XVI International Congress of Phonetic Sciences, 1001-1004. Saarbrücken: Universität Saarbrücken.

Árnason, Kristján. 1999. Icelandic and Faroese. In Harry van der Hulst (ed.), Word prosodic systems in the languages of Europe, 567-586. Berlin/New York: Mouton de Gruyter.

Bailey, Leslie M. 1988. A non-linear analysis of pitch accent in Swedish. Lingua 75. 103-124.

Booij, Geert. 1988. On the relation between lexical and prosodic phonology. In Pier Marco Bertinetto and Michele Loporcaro (eds.), Certamen phonologicum, 63-76. Torino: Rosemberg and Sellier.

Booij, Geert. 1995. The phonology of Dutch. Oxford: Clarendon Press.

Booij, Geert. 1996. Cliticization as prosodic integration: The case of Dutch. The Linguistic Review 13. 219-242.

Bruce, Gösta and Ben Hermans. 1999. Word tone in Germanic languages. In Harry van der Hulst (ed.), Word Prosodic Systems in the Languages of Europe, 605-658. Berlin/New York: Mouton de Gruyter.

Cambier-Langeveld, Tina. 2000. Temporal marking of accents and boundaries. The Hague: Holland Academic Graphics.

Christophe, Anne, Séverine Millotte, Savita Bernal \& Jeffrey Lidz. 2008. Bootstrapping lexical and syntactic acquisition. Language and Speech 51(1\&2). 61-75.

Condoravdi, Cleo. 1990. Sandhi rules of Greek and prosodic theory. In Sharon Inkelas \& Draga Zec (eds.), The phonology-syntax connection, 63-84. Chicago: University of Chicago Press.

Di Sciullo, Anna-Maria \& Edwin Williams. 1987. On the definition of word. Cambridge, Mass.: MIT Press.

Downing, Laura. 1999. Prosodic stem $\neq$ prosodic word in Bantu. In T. Alan Hall \& Ursula Kleinhenz (eds.), Studies on the phonological word, 73-98. Amsterdam: John Benjamins.

Duanmu, San. 1991. Stress and syntax-phonology mismatches: Tonal domains in Danyang and Shanghai. In Dawn Bates (ed.), Proceedings of the 10th West Coast Conference on Formal Linguistics, 127-137. Stanford: SLA.

Eliasson, S. 1986. Sandhi in Peninsular Scandinavian. In Henning Andersen (ed.), Sandhi phenomena in the languages of Europe, 271-300. Berlin: de Gruyter.

Fabb, Nigel. 1998. Compounding. In Andrew Spencer \& Arnold. M. Zwicky (eds.), Handbook of morphology, 66-83. Oxford: Blackwell.

Frota, Sónia. 2000. Prosody and focus in European Portuguese. Phonological phrasing and intonation. New York: Garland Publishing.

Frota, Sónia. 2002. The prosody of focus: A case-study with cross-linguistic implications. In Bernard Bel \& Isabelle Marlien (eds.), Proceedings of Speech Prosody 2002, 319-322. Aixen-Provence, France, Laboratoire Parole et Language and SProSIG.

Frota, Sónia. to appear. Prosodic structure, constituents and their representations. In Abigail C. Cohn, Cécile Fougeron, \& Marie K. Huffman (eds.), Handbook of laboratory phonology, Chapter 9. Oxford. Oxford University Press. 
Frota, Sónia, Mariapaola D’Império, Gorka Elordieta, Pilar Prieto \& Marina Vigário. 2007. Phonetics and phonology of intonational phrasing in Romance. In Pilar Prieto, Joan Mascaró \& Maria-Josep Solé (eds.), Segmental and prosodic issues in Romance phonology, 319-322. Amsterdam: John Benjamins.

Frota, Sónia, Cátia Severino \& Marina Vigário. 2009. Syntactic disambiguation: The role of prosody. Talk given at the Workshop on prosody and meaning, Barcelona, September 1718.

Ghini, Mirco. 1993. $\phi$-formation in Italian: A new proposal. Toronto Working Papers in Linguistics 12.2. 41-79.

Giegerich, Heinz. 2009. Compounding and lexicalism. In Rochelle Lieber \& Pavol Štekauer (eds.), The Oxford handbook of compounding, 178-200 . Oxford: Oxford University Press.

Gonçalves Viana, Aniceto dos Reis. 1883. Essais de phonétique et de phonologie de la langue portugaise d'après le dialect actuel de Lisbonne. Romania 12: 28-98. Reprinted in Estudos de Fonética Portuguesa, 1973, 83-152. Lisboa: Imprensa Nacional - Casa da Moeda.

Green, Anthony Dubach. 2008. Coronals and compounding in Irish. Linguistics 46(2). 193-213.

Gussenhoven, Carlos. 2004. The phonology of tone and intonation. Cambridge: Cambridge University Press.

Gussenhoven, Carlos \& Gösta Bruce. 1999. Word prosody and intonation. In Harry van der Hulst (ed.), Word prosodic systems in the languages of Europe, 233-271. Berlin \& New York: Mouton de Gruyter.

Gussenhoven, Carlos \& Tony Rietvield. 1992. Intonation contours, prosodic structure and preboundary lengthening. Journal of Phonetics 20: 283-303.

Hall, T. Alan. 1999. Phonotactics and the prosodic structure of German function words. In T. Alan Hall \& Ursula Kleinhenz (eds.), Studies on the phonological word, 99-131. Amsterdam: John Benjamins.

Halle, Morris \& Jean-Roger Vergnaud. 1987. An essay on stress. Cambridge, MA: The MIT Press.

Hannahs, Stephen J. 1995a. Glide formation, prefixation, and the phonological word in French. In Jon Amastae, Grant Goodall, Mario Montalbetti \& Marianne Phinney (eds.), Contemporary research in Romance linguistics, 13-24. Amsterdam \& Philadelphia: John Benjamins Publishers.

Hannahs, Stephen J. 1995b. Prosodic structure and French morphophonology. Tübingen: Max Niemeyer Verlag.

Hayes, Bruce. 1989. The prosodic hierarchy in meter. In Paul Kiparsky \& Gilbert Youmans (eds.), Rhythm and meter. Phonetics and Phonology 1, 201-260. New York: Academic Press.

Hayes, Bruce. 1990. Precompiled phrasal phonology. In Sharon Inkelas \& Draga Zec (eds.), The phonology-syntax connection, 85-108. Chicago: University of Chicago Press.

Hayes, Bruce \& Aditi Lahiri. 1991. Bengali intonational phonology. Natural Language and Linguistic Theory 9. 47-96.

Henderson, John. 2002. The word in Eastern/Central Arrernte. In R. M. W. Dixon \& Alexandra Y. Aikhenvald (eds.), Word. A cross-linguistic typology, 100-124. Cambridge: Cambridge University Press.

Hualde, José Ignacio. 2002. Intonation in Romance. Introduction to the special issue. Probus 14(1). 1-7 (Special issue on intonation in Romance, edited by José Ignacio Hualde).

Hualde, José Ignacio. 2006/2007. Stress removal and stress addition in Spanish. Journal of Portuguese Linguistics 5(2)/6(1): 59-89 (Special issue on prosody in Ibero-Romance and related languages, edited by Gorka Elordieta \& Marina Vigário).

Hualde, José Ignacio, Gorka Elordieta, \& Arantzazu Elordieta. 1994. The Basque dialect of Leiketio. Bilbo: Universidad del País Vasco/Euskal Herriko Unibertsitatea.

Hulst, Harry van der. 2010. A note on recursion in phonology. In Harry van der Hulst (ed.), Recursion and human language, 301-342. Berlin: Mouton de Gruyter. 
Hulst, Harry van der, Bernadet Hendriks \& Jeroen van de Weijer. 1999. A survey of word prosodic systems of European languages. In Harry van der Hulst (ed.), Word prosodic systems in the languages of Europe, 425-475. Berlin \& New York: Mouton de Gruyter.

Inkelas, Sharon. 1990. Prosodic constituency in the lexicon. New York: Garland Publishing.

Ito, Junko \& Armin Mester. 1992. Weak layering and word binarity. University of California, Santa Cruz, Ms.

Ito, Junko \& Armin Mester. 2006. Categories and projections in prosodic structure. Paper given at the Old World Conference in Phonology (OCP 4), Rhodes, January.

Ito, Junko \& Armin Mester. 2007. Prosodic adjunction in Japanese compounds. In Miyamoto Yoichi \& Masao Ochi (eds.), Formal approaches to Japanese linguistics: Proceedings of FAJL 4, MIT Working Papers in Linguistics 55, 97-112. Cambridge, MA: MIT, Department of Linguistics and Philosophy.

Jun, Sun-Ah. 1996. The phonetics and phonology of Korean prosody: Intonational phonology and prosodic structure. New York: Garland.

Jun, Sun-Ah. 2005a. Korean intonational phonology and prosodic transcription. In Sun-Ah Jun (ed.), Prosodic typology. The phonology of intonation and phrasing, 201-229. Oxford: Oxford Univerity Press.

Jun, Sun-Ah. 2005b. Prosodic typology. In Sun-Ah Jun (ed.), Prosodic typology. The phonology of intonation and phrasing, 430-458. Oxford: Oxford Univerity Press.

Jun, Sun-Ah. 2007. The intermediate phrase in Korean: Evidence from sentence processing. In Carlos Gussenhoven \& Tomas Riad (eds.), Tones and tunes. Vol. 2: Experimental studies in word and sentence prosody. Phonology \& Phonetics Series, 143-167. Berlin / New York: Mouton de Gruyter.

Kabak, Bariş \& Anthi Revithiadou. 2006. The phonology of clitic groups: Prosodic recursivity revisited. Paper given at The $13^{\text {th }}$ International Conference on Turkish Linguistics. August, Uppsala.

Kabak, Bariş \& Anthi Revithiadou. 2009. An interface approach to prosodic word recursion. In Janet Grijzenhout \& Bariş Kabak (eds.), Phonological domains. Universals and deviations, 15-46. Berlin \& New York: Mouton de Gruyter.

Kabak, Bariş \& Irene Vogel. 2001. The phonological word and stress assignment in Turkish. Phonology 18. 315-360.

Keating, Patricia A. \& Stefanie Shattuck-Hufnagel. 2002. A prosodic view of word form encoding for speech production. UCLA Working Papers in Phonetics 101. 112-156.

Kenstowicz, Michael 1994. Phonology in generative grammar. Cambridge, MA: Blackwell.

Kleinhenz, Ursula. 1996. The prosody of german clitics. In Artemis Alexiadou, Nanna Fuhrhop, Paul Law \& Sylvia Löhken (eds.), ZAS Papers in Linguistics 6, 81-95. Berlin: ZAS.

Kunter, Gero \& Ingo Plag. 2007. What is compound stress? In Jürgen Trouvain \& William J. Barry (eds.), Proceedings of the XVI International Congress of Phonetic Sciences, 10051008. Saarbrücken: Universität Saarbrücken.

Ladd, D. Robert. 1992. Compound prosodic domains. University of Edinburgh, Ms.

Ladd, D. Robert. 1996. Intonational phonology. Cambridge: Cambridge University Press. (2nd ed. 2008).

Leben, William \& Firmin Ahoua. 1997. Prosodic domains in Baule. Phonologv 14. 113-132.

Lees, Robert B. 1961. The phonology of modern standard Turkish, 141-176. Bloomington: Indiana University.

Liberman, Mark \& Richard Sproat. 1992. The stress and structure of modified noun phrases in English. In Ivan A. Sag \& Anna Szabolcsi (eds.), Lexical matters, 131-181. Stanford: Center for the Study of Language and Information.

Mateus, Maria Helena, Ana Maria Brito, Inês Duarte, Isabel Hub Faria, Sónia Frota, Gabriela Matos, Fátima Oliveira, Marina Vigário \& Alina Villalva. 2004. Gramática da língua portuguesa ['Grammar of Portuguese']. (6th ed.) Lisboa: Caminho. 
McCarthy, John J. \& Alan S. Prince. 1994. Generalized alignment. In Geert Booij \& Jaap van Marle (eds.), Yearbook of Morphology 1993, 79-153. Dordrecht: Kluwer Academic Publishers.

Morgan, James L. \& Katherine Demuth. 1996. Signal to syntax: An overview. In James L. Morgan \& Katherine Demuth (eds.), Signal to syntax. Bootstrapping from speech to grammar in early acquisition, 1-22. Mahwah, NJ: Lawrence Erlbaum Associates.

Nash, David. 1986. Topics in Warlpiri grammar. New York: Garland Publishing.

Nespor, Marina. 1999a. The phonology of clitic groups. In Henk van Riemsdijk (ed.), Clitics in the languages of Europe, 865-887. Berlin: Mouton de Gruyter.

Nespor, Marina. 1999b. Stress domains. In Harry van der Hulst (ed.), Word prosodic systems in the languages of Europe, 117-159. Berlin: Mouton de Gruyter.

Nespor, Marina \& Angela Ralli. 1996. Morphology-phonology interface: Phonological domains in Greek compounds. The Linguistic Review 13. 357-382.

Nespor, Marina \& Irene Vogel. 1986. Prosodic phonology. Dordrecht: Foris. Republished 2007 by Mouton de Gruyter, Berlin \& New York.

Nespor, Marina \& Irene Vogel. 2007. Foreword to the second edition. In Prosodic phonology. With a new foreword, xii-xxx. Berlin \& New York: Mouton de Gruyter.

Nespor, Marina \& Wendy Sandler. 1999. Prosody in Israeli sign language. Language and Speech 42(2-3). 143-176.

Pentland, Christina \& Mary Laughren. 2004. Distinguishing prosodic word and phonological word in Walpiri: Prosodic constituency in morphologically complex words. Paper given at the Australian Linguistic Society Annual Conference 2004, Sidney, July.

Peperkamp, Sharon. 1997. Prosodic words. HIL Dissertations 34. The Hague: Holland Academic Graphics.

Pereira, Isabel. 1999. O acento de palavra em português. Uma análise métrica ['Word stress in Portuguese. A metrical analyses']. University of Lisbon dissertation.

Pierrehumbert, Janet \& Mary E. Beckman. 1988. Japanese tone structure. Cambridge, MA: MIT Press.

Pinker, Steven \& Ray Jackendoff. 2005. The faculty of language: What's special about it? Cognition 95(2). 201-236.

Raffelsiefen, Renate. 1999. Diagnostics for prosodic words revisited: The case of historically prefixed words in English. In T. Alan Hall \& Ursula Kleinhenz (eds.), Studies on the phonological word, 133-201. Amsterdam: John Benjamins.

Russell, Kevin. 1999. The "word" in two polysynthetic languages. In T. Alan Hall \& Ursula Kleinhenz (eds.), Studies on the phonological word, 203-221. Amsterdam: John Benjamins.

Sandler, Wendy. 2006. Phonology, phonetics, and the nondominant hand. In Louis Goldstein, Douglas H. Whalen \& Catherine T. Best (eds.), Papers in laboratory phonology 8, 185-212. Berlin \& New York: Mouton de Gruyter.

Schwindt, Luíz Carlos. 2000. O prefixo no Português Brasileiro: Análise morfofonológica ['The prefix in Brazilian Portuguese: Morphophonological analysis']. Pontifícia Universidade Católica do Rio Grande do Sul dissertation.

Selkirk, Elisabeth. 1984. Phonology and syntax. The relation between sound and structure. Cambridge, MA: MIT Press.

Selkirk, Elisabeth. 1986. On derived domains in sentence phonology. Phonology Yearbook 3. 371405.

Selkirk, Elisabeth. 1996. The prosodic structure of function words. In James L. Morgan \& Katherine Demuth (eds.), Signal to syntax: Bootstrapping from speech to grammar in early acquisition, 187-213. Mahwah, NJ: Lawrence Erlbaum Associates.

Selkirk, Elisabeth. 2000. The interaction of constraints on prosodic phrasing. In Merle Horne (ed.), Prosody: Theory and experiment, 231-261. Dordrecht: Kluwer Academic Publishers.

Selkirk, Elisabeth \& Tong Shen. 1990. Prosodic domains in Shanghai Chinese. In Sharon Inkelas and Draga Zec (eds.), The phonology-syntax connection, 313-337. Chicago \& London: The University of Chicago Press. 
Selkirk, Elisabeth, Tahahito Shinya \& Shigeto Kawahara. 2004. Phonological and phonetic effects of minor phrase length on $\mathrm{f} 0$ in Japanese. In Bernard Bel and Isabelle Marlien (eds.), Speech Prosody 2004: Proceedings of the 2nd International Conference on Speech Prosody, 183187. Nara: Japan. ISCA Archive, http://www.isca-speech.org/archive/sp2004.

Truckenbrodt, Hubert. 1995. Phonological phrases: Their relation to syntax, prominence and focus. Ph.D. MIT dissertation.

Truckenbrodt, Hubert. 1999. On the relation between syntactic phrases and phonological phrases. Linguistic Inquiry 3(2). 219-255.

Truckenbrodt. Hubert. 2007. The syntax-phonology interface. In Paul de Lacy (ed.), The Cambridge Handbook of Phonology, 435-456. Cambridge: Cambridge University Press.

Venditti, Jennifer. 2005. The J_ToBI Model of Japanese Intonation. In Sun-Ah Jun (ed.), Prosodic typology. The phonology of intonation and phrasing, 172-200. Oxford: Oxford Univerity Press.

Venditti, Jennifer J., Sun-Ah Jun, Mary E. Beckman. 1996. Prosodic cues to syntactic and other linguistic structures in Japanese, Korean, and English. In James L. Morgan and Katherine Demuth (eds.), Signal to syntax: Bootstrapping from speech to grammar in early acquisition, 287-311. Mahwah, NJ: Lawrence Erlbaum Associates.

Vigário, Marina. 1998. Aspectos da prosódia do português europeu: Estruturas com advérbios de exclusão e negação frásica ('Aspects of European Portuguese prosody: Structures with set divider and negation adverbs'). Braga: Universidade do Minho/CEHUM.

Vigário, Marina. 1999. On the prosodic status of stressless function words in European Portuguese. In T. Alan Hall and Ursula Kleinhenz (eds.), Studies on the phonological word, 255-294. Amsterdam: John Benjamins.

Vigário, Marina. 2003a. The prosodic word in European Portuguese. Berlin/New York: Mouton de Gruyter.

Vigário, Marina. 2003b. Prosody and sentence disambiguation in European Portuguese. Catalan Journal of Linguistics 2. 249-278 (Special Issue on Romance Intonation, edited by Pilar Prieto).

Vigário, Marina. 2006. Sobre o estatuto do grupo clítico e da palavra prosódica composta na hierarquia prosódica ['On the status of clitic groups and compound prosodic words in prosodic hierarchy']. Paper given at XXII Encontro Nacional da Associação Portuguesa de Linguística, Coimbra, October.

Vigário, Marina. 2007. O lugar do grupo clítico e da palavra prosódica composta na hierarquia prosódica: uma nova proposta ['The placement of the clitic group and the compound prosodic word in prosodic hierarchy: a new proposal']. In Maria Lobo \& Maria Antónia Coutinho (eds.), XXII Encontro Nacional da Associação Portuguesa de Linguística. Textos seleccionados, 673-688. Lisboa: Associação Portuguesa de Linguística.

Vigário, Marina \& Sónia Frota. 2002. Prosodic word deletion in coordinate structures. Journal of Portuguese Linguistics 1(2). 241-264.

Villava, Alina. 1994. Estruturas morfológicas. Unidades e hierarquias nas palavras do português ['Morphological structures. Units and hierarchies in Portuguese words']. University of Lisbon dissertation.

Visch, Ellis. 1999. The rhythmic organization of compounds and phrases. In Harry van der Hulst (ed.), Word prosodic systems in the languages of Europe, 161-231. Berlin: Mouton de Gruyter.

Vogel, Irene. 1990. The clitic group in prosodic phonology. In Joan Mascaró \& Marina Nespor (eds.), Grammar in progress, 447-454. Dordrecht: Foris.

Vogel, Irene. 1991. Level ordering in Italian lexical phonology? In Pier Marco Bertinetto, Michael Kenstowicz \& Michele Loporcaro (eds.), Certamen phonologicum II, 81-101. Torino: Rosenberg \& Sellier. 
Vogel, Irene. 2009. The status of the clitic group. In Janet Grijzenhout \& Bariş Kabak (eds.), Phonological domains. Universals and deviations, 15-46. Berlin \& New York: Mouton de Gruyter.

Wennerstrom, Ann. 1993. Focus on the prefix: Evidence for word-internal prosodic words. Phonology 10: 309-324.

Wheeldon, Linda R. \& Aditi Lahiri. 2002. The minimal unit of phonological encoding: Prosodic or lexical word. Cognition 85. B31-B41.

Wiese, Richard. 1996. The phonology of German. Oxford: Clarendon Press.

Zec, Draga and Sharon Inkelas. 1991. The place of clitics in the prosodic hierarchy. In Dawn Bates (ed.), Proceedings of the Tenth West Coast Conference on Formal Linguistics, 505519. Stanford: CSLI. 